\title{
Physical and chemical properties of the regional mixed layer of Mexico's Megapolis Part II: evaluation of measured and modeled trace gases and particle size distributions
}

\author{
C. Ochoa ${ }^{1}$, D. Baumgardner ${ }^{1}$, M. Grutter ${ }^{1}$, J. Allan ${ }^{2}$, J. Fast ${ }^{3}$, and B. Rappenglueck ${ }^{4}$ \\ ${ }^{1}$ Centro de Ciencias de la Atmósfera, Universidad Nacional Autónoma de México, Mexico City, Mexico \\ ${ }^{2}$ University of Manchester, Manchester, UK \\ ${ }^{3}$ Pacific Northwest National Laboratory, Richland, Washington, USA \\ ${ }^{4}$ University of Houston, Houston, Texas, USA \\ Correspondence to: D. Baumgardner (darrel.baumgardner@gmail.com)
}

Received: 16 March 2012 - Published in Atmos. Chem. Phys. Discuss.: 16 April 2012

Revised: 24 September 2012 - Accepted: 16 October 2012 - Published: 5 November 2012

\begin{abstract}
This study extends the work of Baumgardner et al. (2009) in which measurements of trace gases and particles, at a remote, high altitude mountain site, $60 \mathrm{~km}$ from Mexico City were analyzed with respect to the origin of the air masses. In the current evaluation, the temperature, water vapor mixing ratio (WMR), ozone $\left(\mathrm{O}_{3}\right)$, carbon monoxide $(\mathrm{CO})$, sulfur dioxide $\left(\mathrm{SO}_{2}\right)$ and acyl peroxy nitrate $(\mathrm{APN})$ are simulated with the WRF-Chem chemical transport model and compared with the measurements at the mountain site. Comparisons between the model and measurements are also evaluated for particle size distributions (PSDs) of the mass concentrations of sulfate, nitrate, ammonium and organic mass $(\mathrm{OM})$. The model predictions of the diurnal trends in temperature, WMR and trace gases were generally well correlated; 13 of the 18 correlations were significant at a confidence level of $<0.01$. Less satisfactory were the average hourly differences between model and measurements that showed predicted values within expected, natural variation for only 10 of the 18 comparisons. The model performed best when comparing with the measurements during periods when the air originated from the east. In that case all six of the parameters being compared had average differences between the model and measurements less than the expected standard deviation. For the cases when the air masses are from the southwest or west northwest, only two of the comparisons from each case showed differences less than the expected standard deviation. The differences appear to be a result of an overly rapid growth of the boundary layer predicted
\end{abstract}

by the model and too much dilution. There also is more $\mathrm{O}_{3}$ being produced, most likely by photochemical production, downwind of the emission sources than is predicted by the model.

The measured and modeled PSD compare very well with respect to their general shape and the diameter of the peak concentrations. The spectra are log normally distributed with most of the mass in the accumulation mode centered at $200 \pm 20 \mathrm{~nm}$ and little observed or predicted changes with respect to the time when the RML is above the Altzomoni research station. Only the total mass changes with time and air mass origin. The invariability of average diameter of the accumulation mode suggests that there is very little growth of the particles by condensation or coagulation after six hours of aging downwind of the major sources of anthropogenic emissions in Mexico's Megapolis. This could greatly simplify parameterization in climate models although it is not known at this time if this invariance can be extended to other megacity regions.

\section{Introduction}

The role of aerosol particles in modulating climate and their link to various health related issues has been clearly documented with numerous observational and theoretical studies (Molina et al., 2010 and references therein). Megacities are a major source of these particles and in particular Mexico City 
has been the focus of a number of major field programs since the early 1990's that studied the sources and evolution of these particles, as well as other anthropogenic emissions. For example, the first of these projects was the Mexico City Air Quality Research Initiative (MARI) conducted from 19901994 (LANL/IMP, 1994; Streit and Guzman, 1996), followed by the IMADA-AVER (Investigación sobre Materia Particulada y Deterioro Atmosférico, Aerosol and Visibility Evaluation Research) campaign in February-March 1997 (IMP, 1998; Doran et al., 1998; Edgerton et al., 1999; Molina and Molina, 2002). The third experiment was the Mexico City Metropolitan Area field experiment (MCMA-2003), an intensive 5-week campaign that took place in the spring of 2003 (31 March-4 May), with the goal of investigating the atmospheric chemistry of the MCMA, with particular focus on secondary PM formation (Molina et al., 2007). Most recently, the Megacity Initiative: Local And Global Research Observations (MILAGRO) project was carried out in March 2006 (Molina et al., 2010) during which time continuous observations of gas and particle concentrations were taken at various locations across Mexico City and its surroundings.

The environmental impact of these urban aerosols, a large fraction of them subsequently transported from the city, depends on their size-differentiated composition. Their lifetime, interaction with solar radiation, capacity to form cloud droplets and crystals and facility in entering the human respiration system is highly sensitive to how the mass and composition of these particles are distributed by size. Hence an important aspect of particles transported from the Mexican Megapolis is that of how their size distribution evolves; however, there have been very few studies that have looked in detail at the size distributions of aerosol particles either in Mexico City or in nearby regions. Baumgardner et al. (2000) were the first to show the evolution of the number and volume size distributions in Mexico City. Measurements of nano-sized particle distributions, $<30 \mathrm{~nm}$, were made during MCMA2003 (Dunn et al., 2004) indicating that new particle formation occurred during periods of elevated sulfur dioxide. During this same project Salcedo et al. (2006) measured for the first time the size differentiated masses of selected inorganic and organic ions with an aerosol mass spectrometer (AMS). The size distributions were dominated by a prominent accumulation mode where inorganic and organic species appeared to be internally mixed most of the time, and by a smaller externally-mixed organic mode that was likely related to traffic emissions. During MILAGRO, although there were many instruments in operation that measured the size distributions of the aerosol particles, only four studies have thus far been published that discuss the evolution of particle size distributions (PSD). Smith et al. (2008) studied new particle formation with measurements of nanoparticles. Kleinman et al. (2009) evaluated the PSD characteristics as a function of time of day and photochemical age. Lewandowski et al. (2010) derived column averaged PSDs from sun photometer measurements and Wang et al. (2010) compared PSDs with measurements of $\mathrm{CCN}$. There have been no published evaluations of the PSDs using numerical models, although Kleinman et al. (2009) did make calculations of condensational growth to compare with their observations.

It is the primary objective of the study described herein, to complement the evaluation by Baumgardner et al. (2009) who looked at the physical and chemical properties of the regional mixed layer (RML) of Mexico's Megapolis during the MILAGRO project. In that study, the diurnal trends of selected chemical species were evaluated at an elevated site southeast of Mexico City. The focus of that study was to analyze the diurnal trends of selected trace gases and inorganic and organic ions as the RML reached the elevation of the research site. The current study expands upon that evaluation by analyzing the diurnal trends in the measured particle size distributions (PSD) of sulfate, nitrate, ammonium and organic mass (OM). The Weather Research Forecast (WRF) with Chemistry (Chem) is also implemented to compare with the measurements and offer additional insight with respect to the observed trends.

The RML, as introduced by Baumgardner et al. (2009), is a name given to the boundary layer air that eventually reaches the research site. The mixed layer, also known as the convective boundary layer, is formed when the sun warms the ground and subsequently heats the air, creating shallow thermals that rise and cause mixing. As defined in the Baumgardner et al. (2009) study, and used in this evaluation as well, the RML is the boundary layer air that reaches the research site and whose properties are dependent on the air mass history. We assume that the composition of the RML is largely formed from the emissions by the closest, major source region, but will be modified by other primary and secondary anthropogenic and natural sources before reaching the research site. The area of interest is that of the Mexican Megapolis, i.e. the region encompassing the major population centers of Mexico City, Cuernavaca-Cuautla and Puebla. The chemical composition of the RML measured at the research site will depend on the relative distance from the strongest sources of emissions with horizontal and vertical mixing by solar heating and mechanical turbulence leading to a more homogeneous mixture as the air masses are advected by the larger scale circulation. We sample these air masses as they pass the Altzomoni research site, giving us a series of data points from which we can observe the diurnal trends in gas and particle composition in the upper portions of the RML.

In the following presentation we describe observations of average diurnal trends in the mass size distributions of sulfate, nitrate, ammonium and organic matter and compare these observations with simulations from the WRFChem model. We first describe the experimental methodology, compare simulated and measured chemically speciated PSDs, along with several other atmospherically relevant parameters, and finish with a discussion of the results and concluding remarks. 


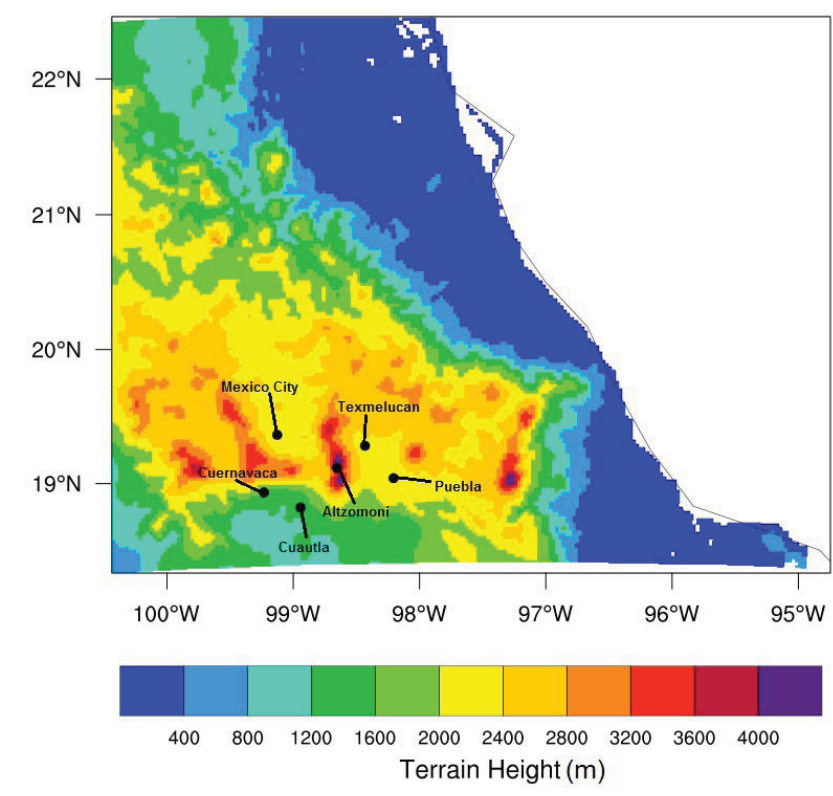

Fig. 1. This diagram shows the inner domain used in the WRFChem model, at a resolution of $3 \times 3 \mathrm{~km}$. The color coding refers to elevation (m.a.s.l.). The research site, Altzomoni, along with three locations centered in regions of high anthropogenic pollution, are also shown. The areas of Mexico City, Cuautla and Texmelucan are upwind of Altzomoni when air originates from the WNW, SW and E, respectively.

\section{Experimental method}

\subsection{Measurements}

During March 2006 measurements of meteorological conditions, trace gas concentrations and aerosol particle properties were made with instruments deployed at the Altzomoni overlook that is situated inside the national park Izta-PopoZoquiapan on the saddle called the Paso de Cortés situated between the volcanoes Popocatépetl and Iztaccíhuatl. The site is located at $19.117^{\circ} \mathrm{N}, 98.654^{\circ} \mathrm{W}$ (see Fig. 1) with an altitude of $4010 \mathrm{~m}$ a.s.l. (Baumgardner et al., 2009), approximately $1770 \mathrm{~m}$ above the Mexico City basin.

The atmospheric parameters measured at Altzomoni and the techniques employed are described in detail by Baumgardner et al. (2009). Here we briefly summarize those measurements used for the current study (technical specifications are listed in Table 1). Meteorological variables (temperature, relative humidity, wind direction and speed), averaged at one minute intervals, were measured with a commercial weather station (Davis Instruments) at two meters a.g.l. An openpath FTIR was used to measure gas concentrations of carbon monoxide $(\mathrm{CO})$, ozone $\left(\mathrm{O}_{3}\right)$ and sulfur dioxide $\left(\mathrm{SO}_{2}\right)$, among other gases. These parameters were acquired over one minute averaging intervals. Peroxyacetyl nitrate (PAN) and peroxypropionyl nitrate (PPN) measurements were carried out with a dual column gas chromatograph using an electron capture detector (Metcon Inc., Königstein, Germany). These measurements were averaged every ten minutes.

Total particle number concentration for sizes larger than $50 \mathrm{~nm}$ was measured with a condensation nuclei $(\mathrm{CN})$ counter model 3010 (TSI, St. Paul, MN), at a rate of $1 \mathrm{~Hz}$. A quadrupole AMS (Aerodyne Research Inc, Billerica, MA) provided the mass concentrations of inorganic ions (sulfate, nitrate, and ammonium) and the organic fraction in the submicron particulate matter. The AMS was operated with a time resolution of five minutes (Jayne et al., 2000; Jimenez et al., 2003; Canagaratna et al., 2007). The collection efficiency of 0.5 was derived by comparing the total volume derived from a scanning mobility particle sizer (SMPS) with the volume derived from the AMS mass concentrations over the same size range as the SMPS as discussed by Baumgardner et al. (2009). It is important to mention that all the particle measurement instruments were connected to an inlet with a $\mathrm{PM}_{1.0}$ cyclone separator (University Research Glassware, Chapel Hill, N.C.).

Baumgardner et al. (2009) selected fourteen days for evaluation: 3-4, 12-19 and 28-31 March. These periods had clear skies, did not show obvious influence from biomass burning, and both visual observations and $\mathrm{CN}$ concentrations showed a distinct transition from free tropospheric air at the measurement site to air from the RML as it grew beyond the altitude of Altzomoni and visibility decreased significantly (Baumgardner et al., 2009).

In the studies reported here, we focus on a subset of these periods, 12-19 March and 28-29 March. As in the analysis of Baumgardner et al. (2009), who used the wind fields derived from the North American Regional Reanalysis (NARR) at $650 \mathrm{mb}$ (the average pressure measured at Altzomoni was $630 \mathrm{mb}$ ), we distinguish among different wind direction sectors according to the origin of the air mass during the previous $24 \mathrm{~h}$. The larger scale circulation brought air from the East (E) during the 12, 13, 14, 16, 17, 29 March, southwest (SW) during the 18, 19 of March and west northwest (WNW) on the 15 and 28 March.

\subsection{Model description and configuration}

WRF/Chem is a chemical transport model that couples the Weather Research and Forecasting community model with atmospheric chemistry modules to simulate the evolution of trace gas and particle properties (Grell et al., 2005). The code used in the current study is the Pacific Northwest National Laboratory (PNNL) modified rendition of WRF/Chem version 3 for Mexico City and surroundings (Fast et al., 2009). Table 2 lists the modules used in the simulation. The meteorology is described by Skamarock et al. (2008), the gas phase chemistry uses the carbon bond mechanism (CBM-Z, Zaveri and Peters, 1999) and the photolysis scheme is a simplified version of the Tropospheric Ultraviolet-Visible (TUV) model (Madronich, 1987) named fast-TUV (Tie et al., 2003). For the particulate phase the MADE/SORGAM (Modal Aerosol 
Table 1. Instrumentation at the Altzomoni research site.

\begin{tabular}{|c|c|c|c|c|c|}
\hline Parameter & Instrument & Institute & $\begin{array}{l}\text { Detection } \\
\text { Limits }\end{array}$ & Accuracy & $\begin{array}{l}\text { Sample } \\
\text { Rate }\end{array}$ \\
\hline $\begin{array}{l}\text { State } \\
\text { Parameters } \\
\text { Temperature } \\
\text { RH }\end{array}$ & Davis Inc. & UNAM & $\begin{array}{l}-50 \text { to }+50 \mathrm{C} \\
0 \text { to } 100 \%\end{array}$ & $\begin{array}{l} \pm 1 \\
\pm 5 \%\end{array}$ & $\begin{array}{l}\text { One minute } \\
\text { averages }\end{array}$ \\
\hline $\begin{array}{l}\mathrm{CO}, \mathrm{O}_{3} \\
\mathrm{SO}_{2}\end{array}$ & $\begin{array}{l}\text { Active Open- } \\
\text { path FTIR }\end{array}$ & UNAM & $\begin{array}{l}.001 \mathrm{ppm} \\
0.01 \mathrm{ppm}\end{array}$ & $\begin{array}{l} \pm 15 \% \\
\pm 30 \%\end{array}$ & $\begin{array}{l}10 \mathrm{~s} \text { aver- } \\
\text { ages }\end{array}$ \\
\hline $\mathrm{CN}$ & TSI 3010 & UNAM & $0.05 \mu \mathrm{m}$ & $\pm 15 \%$ & $1 \mathrm{~Hz}$ \\
\hline $\begin{array}{l}\mathrm{SO}_{4}, \mathrm{NO}_{3}, \\
\mathrm{NH}_{4}, \mathrm{OC}\end{array}$ & $\begin{array}{l}\text { Aerodyne } \\
\text { AMS }\end{array}$ & $\begin{array}{l}\text { Scripps/UN } \\
\text { AM/U. } \\
\text { Manchester }\end{array}$ & $0.1 \mu \mathrm{g} \mathrm{m}^{-3}$ & $14 \%$ & $\begin{array}{l}\text { One minute } \\
\text { averages }\end{array}$ \\
\hline PAN/PPN & $\begin{array}{l}\text { Metcon } \\
\text { GC/ECD }\end{array}$ & U. Houston & $25 / 35 \mathrm{pptv}$ & $\pm 15 \%$ & $\begin{array}{l}\text { One minute } \\
\text { averages }\end{array}$ \\
\hline
\end{tabular}

Dynamics model for Europe coupled with the Secondary Organic Aerosol Model) aerosol model (Ackermann et al., 1998; Schell et al., 2001) is used. The MADE/SORGAM simulates the aerosol size distribution using a modal approach for three different modes: Aitken, accumulation and coarse, using two overlapping lognormal modes for the submicrometer aerosols (Ackermann et al., 1998). This configuration was selected based on the experience of some in-house tests and the expertise provided by Jerome Fast (PNNL, 2009).

The simulation covers two regions, an inner domain that encompasses the central region of Mexico with a $3-\mathrm{km}$ grid spacing (Fig. 1) and an outer domain that covers the whole country with a $12-\mathrm{km}$ grid spacing (not shown). The initial and boundary conditions are the same as those used by Fast et al. (2009), but with the modified speciation to use the CBM$\mathrm{Z}$ coupled with the MADE/SORGAM aerosol model.

The meteorological variables for the initial and boundary conditions were obtained in six hour intervals from the Global Forecast System (GFS) model maintained by the National Center for Environmental Prediction (NCEP). Other variables like initial sea surface temperatures, soil temperatures and moisture were also retrieved from the GFS. The initial and boundary conditions for trace gases and particles were obtained in 6-h intervals from the output of the global chemistry model MOZART-4 (Pfister et al., 2008).

The emissions inventories of trace gas and particles used in this study, described by Fast et al. (2009), are based on the 1999 US National Emissions Inventory (NEI) and adjusted by Lei et al. (2007) with the 2002 Mexico City Metropolitan Area (MCMA) inventory developed by the Comision Ambiental Metropolitana (CAM, 2004). In order to take into account the emissions fluctuations between weekdays and weekends, the weekday mobile emissions were diminished by $10 \%$ and $30 \%$ for Saturdays and Sundays respectively
(Fast et al., 2009; Lei et al., 2007). The volatile organic compounds (VOC) emissions were adjusted to update industrial, road and area emissions as in Lei et al. (2007) for the Mexico City basin while for the grid cells outside this area the 1999 NEI is used. The base year for this inventory is 1999 and was the first emissions inventory developed for the whole country. Emissions were estimated for each state and municipality for six pollutants: nitrogen oxides $\left(\mathrm{NO}_{\mathrm{x}}\right)$, sulfur oxides $\left(\mathrm{SO}_{\mathrm{x}}\right)$, volatile organic compounds (VOC), carbon monoxide, particulate matter less than 10 and 2.5 micrometers $\left(\mathrm{PM}_{10} / \mathrm{PM}_{2.5}\right)$ and ammonia. Estimates of emissions of these compounds were made taking into account fixed and area sources, motor vehicles, mobile sources that do not circulate on roads and natural sources (INE-SEMARNAT, 2006). Baumgardner et al. (2009) reported that in the area to the east of Mexico City, between the main urban area and the measurement site, there are no major sources of anthropogenic pollutants, although the small villages in this region may have some minor impact. There are, however, two important natural sources of trace gases and particles: biogenic emissions (from vegetation and biomass burning) and volcanic exhalations.

The Popocatepetl volcano, with strong, intermittent emissions of sulfur dioxide $\left(\mathrm{SO}_{2}\right)$, has an impact on atmospheric chemistry and secondary aerosols production (Grutter et al., 2008). Due to this intermittency, the volcano emissions are highly variable and this feature is addressed in the model by adding to the emissions inventory an emission rate that varies day to day according to observations.

Trees, bushes and grasses emit organic compounds, some of them in response to environmental stress. These highly volatile and reactive compounds can alter significantly the atmospheric chemistry (Dominguez-Taylor et al., 2007). The most abundant compounds are the isoprenoids (Guenther et al., 1995). The isoprene and terpene emissions are taken into 
Table 2. Selected WRF-Chem configuration.

\begin{tabular}{ll}
\hline Process & WRF-Chem Option \\
\hline Advection & Positive Definite \\
Long wave radiation & RRTM \\
Shortwave radiation & Goddard \\
Surface layer & MM5 similarity theory \\
Land surface & unified Noah land-surface \\
& model \\
Boundary layer & YSU \\
Cloud microphysics & Enhanced Purdue Lin \\
Photolysis & Madronich FTUV \\
Gas phase chemistry & CBM-Z \\
Aerosol chemistry & MADE/SORGAM \\
\hline
\end{tabular}

account using the Model of Emissions of Gases and Aerosols from Nature (MEGAN). MEGAN is a global model with a resolution of $\sim 1 \mathrm{~km}^{2}$ and estimates the emission rate of isoprene using canopy-scale emission factors, calculating the emissions for each plant functional type and summing them to estimate the total emission in a defined area (Guenther et al., 2006).

Another significant emission source is the burning of biomass (Yokelson et al., 2007; Molina et al., 2007; DeCarlo et al., 2008; Aiken et al., 2009). Fast et al. (2009) computed the daily fire emissions of trace gas and particles from the MODIS (Moderate Resolution Imaging Spectroradiometer) thermal anomalies product using the methodology described by Wiedinmyer et al. (2006). These emissions are also part of the inventory used for the present study.

The structure of the planetary boundary layer (PBL) is simulated in WRF/Chem using the Yonsei University parameterization reported by Hong et al. (2006), setting a minimum value of the PBL height at $200 \mathrm{~m}$ a.g.l. when there is no solar heating. This scheme is a vertical diffusion package with non-local turbulent mixing in the PBL and is the next generation of the medium range forecast PBL implemented by Hong and Pan (1996). This new version adds an explicit treatment to the entrainment layer at the top of the PBL based on the studies reported by Noh et al. (2003) (Skamarock et al., 2008).

\section{Results}

\subsection{Analysis methodology}

The fidelity of the model with respect to its accuracy in predicting the temporal properties of the atmospheric constituents is evaluated in two ways: (1) by comparing the relative trends in the measured, diurnal averages made at the Altzomoni research site with averages from the simulation, both in hourly intervals and (2) by comparing the average difference between the measured and modeled parameters over

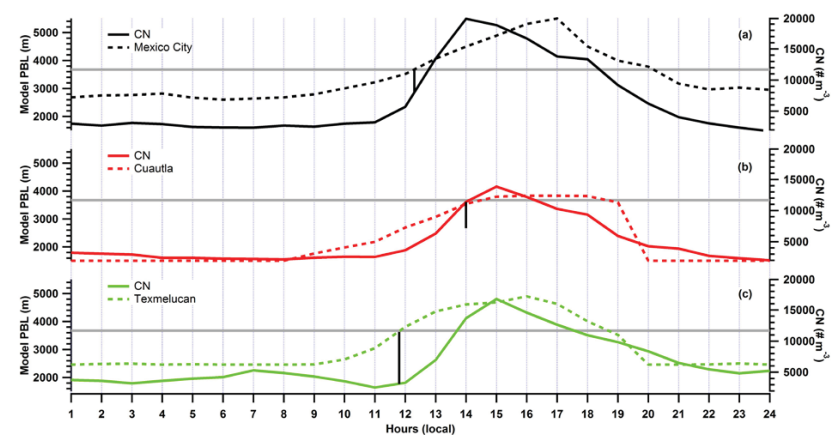

Fig. 2. Hourly averages of the simulated boundary layer depth (a.s.1.), drawn as dashed lines and observed $\mathrm{CN}$ concentration (solid lines) are shown here for time periods when air originates from (a) the west northwest (Mexico City), (b) southwest (Cuautla) and (c) east (Texmelucan). The grey line is a reference for the Altzomoni research site altitude and the vertical black lines show the time when the simulated RML reaches the Altzomoni measurement site.

the $24 \mathrm{~h}$ periods. All times are reported as local standard time (LST, UTC-6h).

The comparisons are partitioned into the three cases mentioned above, i.e. air masses arriving from the E, SW and WNW. In order to evaluate the differences in the evolution of gas and particle properties with respect to these three cases, as measured and simulated, the data are binned with respect to the hour of the day, to account for the different number of days for the three cases.

The primary focus of the evaluation is on the time evolution of the size distributed mass concentrations measured with the AMS compared to the log normal PSDs produced by the model. Prior to discussing these comparisons, however, we investigate the simulation of the meteorological parameters and several trace gases in comparison with the observation. A reasonable agreement between the simulated and measured meteorological and gas variables is a prerequisite for an accurate prediction of the PSDs. Trends in the meteorological and trace gas variables also provide additional insight to changes in the characteristics of the PSDs. As we are interested in trends, as well as absolute values, for the comparison of meteorology and gases we calculate the Pearson's correlation coefficient (Bevington and Robinson, 2003) to quantify the relationship between the measured and simulated trends. The absolute differences are calculated as the sum of the average hourly differences between the measured and simulated parameters. As will be observed in Figs. 3-5, discussed below, some of the measured and simulated variables had very similar daily trends but appeared to be shifted with respect to one another in time. Hence, an additional step was taken in which the correlation coefficients and sum of the differences were calculated after shifting the simulated time series by plus or minus several hours to see if the correlations would improve and differences would decrease with 
Table 3. Statistical parameter summary.

\begin{tabular}{|c|c|c|c|c|c|c|c|c|c|c|c|c|c|c|c|}
\hline \multirow[b]{2}{*}{ Properties } & \multicolumn{5}{|c|}{ WNW } & \multicolumn{5}{|c|}{ SW } & \multicolumn{5}{|c|}{$\mathrm{E}$} \\
\hline & Lag & Corr. & $\mathrm{Pc}$ & Diff & Std. & Lag & Corr. & $\mathrm{Pc}$ & Diff & Std. & Lag & Corr. & Pc & Diff & Std. \\
\hline Temp. & 0 & 0.93 & 0.001 & -1.4 & 0.09 & 0 & 0.90 & 0.001 & -0.58 & 0.81 & 0 & 0.92 & 0.001 & 0.765 & 1.53 \\
\hline WMR & 0 & 0.89 & 0.001 & 0.86 & 0.11 & 2 & 0.76 & 0.001 & -0.75 & 0.47 & 2 & 0.52 & 0.013 & 0.137 & 1.45 \\
\hline $\mathrm{CO}$ & 2 & -0.22 & 0.329 & -0.004 & 0.01 & 2 & 0.73 & 0.001 & -0.025 & 0.01 & 2 & 0.91 & 0.001 & -0.020 & 0.15 \\
\hline $\mathrm{SO}_{2}$ & -1 & -0.65 & 0.001 & 0.031 & .01 & -1 & 0.44 & 0.034 & 0.119 & .01 & 2 & -0.53 & 0.052 & 0.008 & 0.31 \\
\hline $\mathrm{O}_{3}$ & 2 & 0.60 & 0.003 & -0.029 & 0.01 & 1 & 0.60 & 0.003 & -0.016 & 0.01 & -2 & 0.61 & 0.003 & -0.020 & 0.06 \\
\hline APN & 1 & 0.64 & 0.001 & 0.208 & 0.22 & 1 & 0.95 & 0.001 & 0.057 & 0.07 & -2 & 0.33 & 0.129 & 0.148 & 0.25 \\
\hline
\end{tabular}

Lag is defined as the time shift of the model with respect to the measurements (model- measurements).

Corr. = correlation coefficient

$\mathrm{Pc}=$ the significance level of the correlation coefficient

Diff $=$ the average difference between the model and measurements,

Std. = Average, hourly standard deviation of the measurements over the total period for each air mass case

WMR=water mixing ratio

Gray Shaded boxes highlight statistically significant correlation coefficients.

Green shaded boxes highlight average differences smaller than the average, hourly standard deviation.

time shifts. The results of these statistics are summarized in Table 3.

In order to assess the magnitude of the average hourly differences between the modeled and measured meteorological and trace gas parameters, they are compared in Table 3 with the natural variability derived from the measurements. For each of the air mass cases, the measured data were averaged over five minute intervals for all the days of each case. These data were then stratified by hour of the day and the standard deviation within each hour interval calculated. The average standard deviation, for each case and each atmospheric variable, is calculated as the sum of the hourly standard deviations divided by the 24 values.

As an additional means of observing the degree of variability and the relationship between the measured and modeled meteorological and trace gas values, dispersion plots were made of the model versus measured hourly values, and a least-square regression calculated. These figures, and the associated slopes and intercepts may be found in the supplementary material.

\subsection{Boundary layer growth and meteorology}

The diurnal trend of the atmospheric parameters is directly related to the physics of the boundary layer (BL) growth, i.e. solar heating, sensible heat flux from the ground, wind shear, turbulent mixing and larger scale circulations (Stensrud, 2007). In addition, the solar radiation that produces the energy to generate turbulence is also responsible for driving the photochemical processes that produce $\mathrm{O}_{3}$, PAN and secondary aerosols like sulfates, nitrates and some of the organics. Biogenic emissions are sensitive to the solar heating, as well. Hence, by analyzing the simulations of the BL thickness in relation to the diurnal cycles of the modeled and observed atmospheric parameters, we gain insight that helps us assess the accuracy of the model.

Three locations, related to the air mass origin, were selected for evaluating the diurnal cycles. The locations cho- sen to represent locations upwind from the measurement site to the WNW, E and SW were Mexico City, Texmelucan and Cuautla (see Fig. 1), respectively. These locations were selected for their proximity to the major population centers but far enough from Altzomoni to be unaffected by local topographical features. Their distances from Altzomoni were $60 \mathrm{~km}, 30 \mathrm{~km}$ and $45 \mathrm{~km}$, respectively. Baumgardner et al. (2009) showed that the CN concentration, as well as trace gases like CO increase rapidly when the depth of the boundary layer in Mexico City (Shaw et al., 2007) grew to $1700 \mathrm{~m}$ a.g.l., i.e. the altitude of Altzomoni. As shown in Fig. 2 the average, measured $\mathrm{CN}$ concentrations for the three cases increases rapidly when the simulated RML is in close proximity to the altitude of the measurement site. The horizontal, solid gray lines in this figure show the altitude in the model of the research site. Note that this altitude is about $300 \mathrm{~m}$ lower than the actual height of the research site as a result of the model resolution. The solid curve in each of the three panels is the average diurnal time series of the $\mathrm{CN}$ concentration measured at the site. As was shown by Shaw et al. (2007), the BL in the Mexico City area routinely grows to depths greater than $4000 \mathrm{~m}$ a.g.l., as shown by the model results. The short, vertical black lines connecting the measured $\mathrm{CN}$ and moldeled RML depth are drawn at the time when the simulation shows that the top of RML is at the same level as Altzomoni.

As previously mentioned, the $\mathrm{CN}$ concentration is an indicator of $\mathrm{t}$ when the air from the RML reaches the research site (Baumgardner et al., 2009). Before this time, the concentrations are quite low, less than $2000 \mathrm{~cm}^{-3}$ (Fig. 2), reflecting the presence of free tropospheric air. As the RML grows and mixes with the local environment, the concentrations begin to increase and reach a maximum, usually when the aerosol layer that forms at the top of the RML passes the site as the layer continues to grow (Raga et al., 2001; Baumgardner et al., 2009). If the growth is correctly simulated, when the top of the RML approaches the altitude of the research site we 

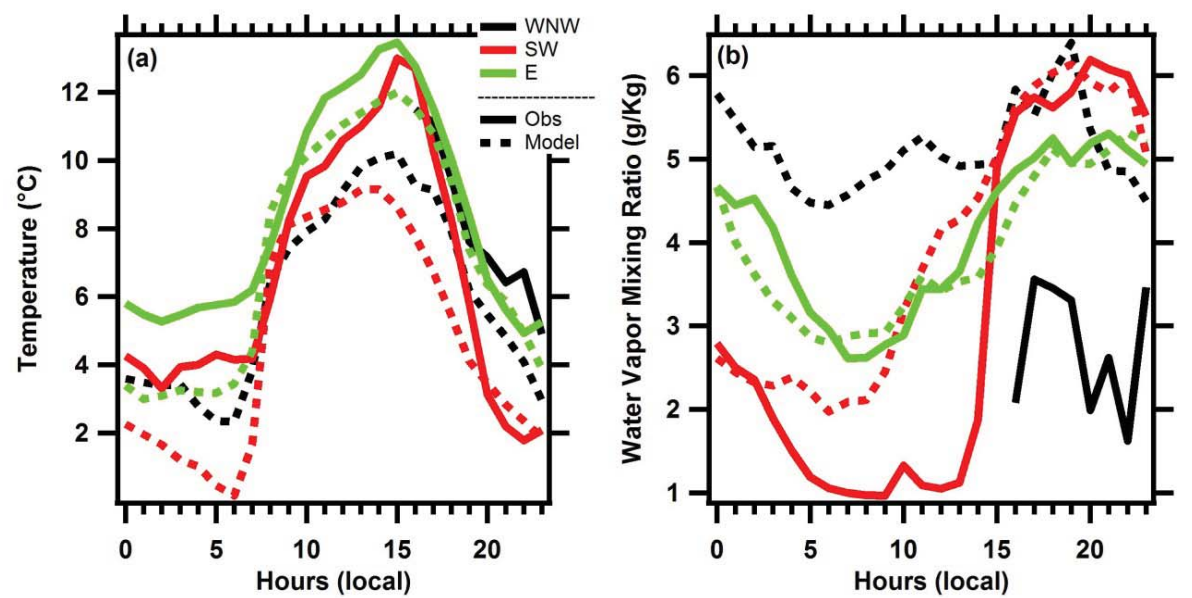

Fig. 3. Measured (solid line) and simulated (dashed) daily trends in(a) temperature and(b) water vapor mixing ratios for the three cases related to air mass origin, i.e. east (E, green), southwest (SW, red) and west northwest (WNW, black).

should see the $\mathrm{CN}$ concentrations start to increase, keeping in mind that larger scale circulations are also important for lifting the RML up the mountain site.

We note several features when comparing the time when the simulated RML reaches the research site to the increase in $\mathrm{CN}$ concentration. In Fig. 2a, when the origin of the general air mass is from the WNW, we observe a slight increase in the $\mathrm{CN}$ just prior to the time when the RML depth in Mexico City is the same as the altitude of Altzomoni. As the RML reaches Altzomoni between 1100 and 1200, the CN concentration begins increasing rapidly before decreasing after 1400. The RML is continuing to grow but the $\mathrm{CN}$ is diluted as the RML mixes with the local environment.

For the case of air originating from the SW (Fig. 2b), according to the model results the RML depth barely exceeds the height of the research site, broaching that altitude after 13:00 and then remaining constant for five hours before collapsing in the afternoon at 18:00. The delay in reaching its maximum depth, compared to the case of winds from the WNW, explains the observed delay in the increase in the $\mathrm{CN}$ concentration when winds are from the SW. The two hour difference between when the simulated RML at Cuautla reaches its maximum, compared to the simulated maximum for the RML in Mexico City and Texmelucan, can be attributed to two factors (1) the difference in time when the sun begins heating each location (Fast and Zhong, 1998, Whiteman et al., 2000) and (2) the difference in altitudes. Cuautla remains in the shadow of the mountains at that time of the year until around 10:00 whereas Mexico City and Texmelucan receive solar warming between 08:00 and 09:00. Cuautla is also $1000 \mathrm{~m}$ lower than either Mexico City or Texmelucan, hence more time is needed for the boundary layer to grow and reach the altitude of the research site. In Fig. 2c, we observe a small increase in the $\mathrm{CN}$ concentration at the time the model predicts the arrival of the RML at the measure- ment site but the more significant increase doesn't begin until an hour later when the predicted RML is about $200 \mathrm{~m}$ above Altzomoni. This is very similar to what was observed when the air masses originated from the WNW (Fig. 2a). To summarize the RML results, they are generally consistent with the $\mathrm{CN}$ data and indicate that the atmospheric physics is well represented in the model; however, it is important to note that there is a time lag of approximately one hour between when the simulated RML reaches the Altzomoni site and when the $\mathrm{CN}$ concentration starts to increase rapidly (e.g. 1100 and 1200 , respectively, for the WNW).

Figure 3 shows the diurnal averages of the temperature and water vapor mixing ratios that were measured and simulated for the three periods. The truncation of the observations prior to 1600 , when the air originated from the WNW, is due to a problem during those days with the download of data from the weather station. On average, the measured temperatures for all three cases are $2-4{ }^{\circ} \mathrm{C}$ warmer than predicted; however, the model does best with the prediction of temperature when air masses originate from the east. The average differences in the model and observations in air masses from the $\mathrm{E}$ and SW, however, are within the natural variability as compared to the average measured standard deviation as shown in Table 3.

The agreement between simulated and measured water vapor mixing ratio (Fig. 3) is generally good in the easterly air masses over the $24 \mathrm{~h}$. In the air from the SW the model agrees well with the observations in the afternoon and evening after 15:00 but overestimates the mixing ratio by factors of two to four in the morning through mid-afternoon. The water vapor mixing ratio is also overestimated by up to a factor of two in the WNW case. Only for the easterly air masses is the average difference between simulated and observed water vapor mixing ratios smaller than the natural variability (Table 3 ). 

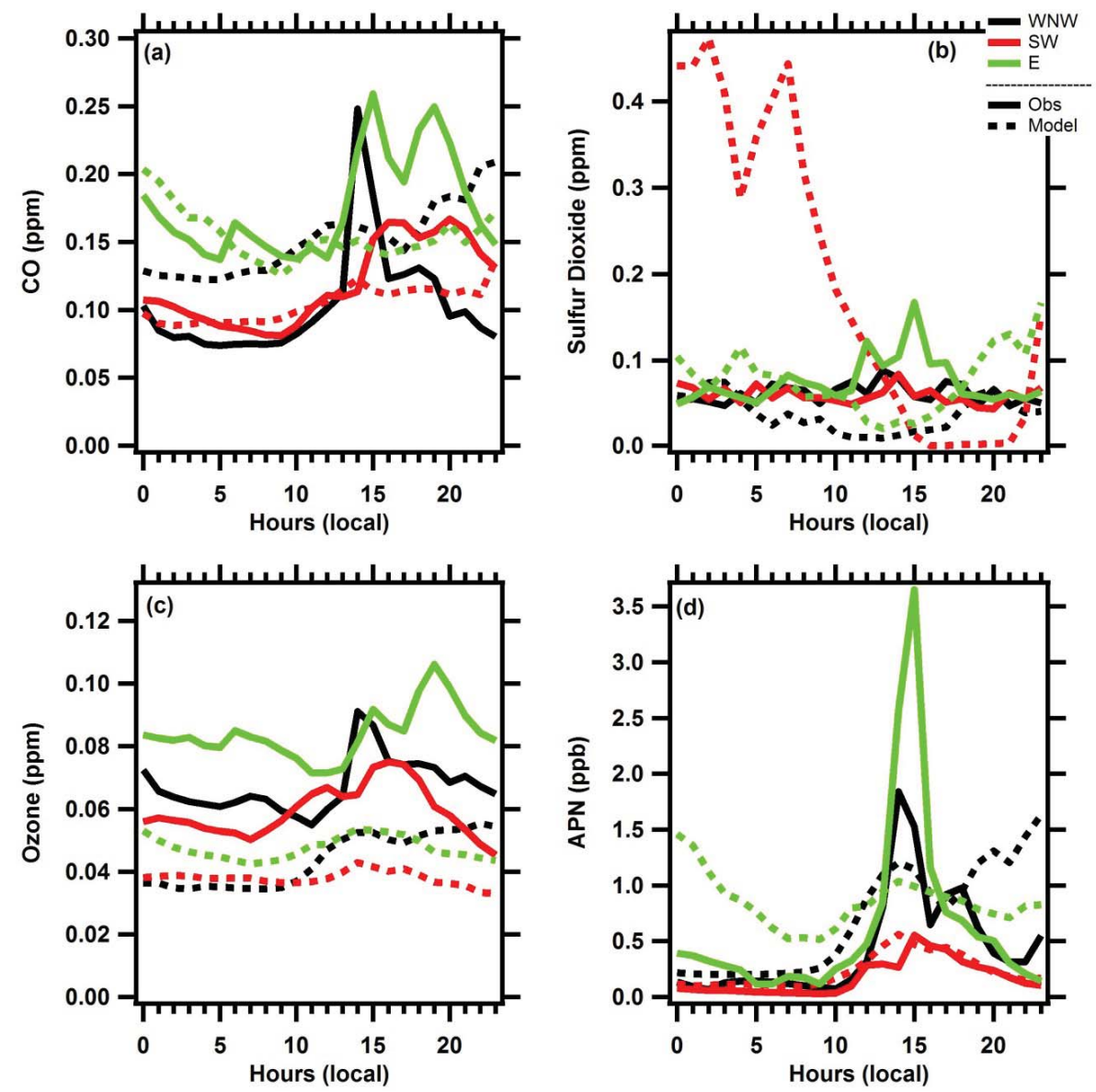

Fig. 4. The average simulated (dashed lines) and observed (solid lines) mixing ratios for: (a) carbon monoxide (CO), (b) Sulfur dioxide $\left(\mathrm{SO}_{2}\right)$, (c) Ozone $\left(\mathrm{O}_{3}\right)$ and $(\mathbf{d})$ acyl peroxy nitrate $(\mathrm{APN})$ are shown here as a function of the air mass origin.

\subsection{Trace gas species}

The trace gases evaluated in this study were $\mathrm{CO}, \mathrm{O}_{3}, \mathrm{SO}_{2}$ and the sum of PAN and PPN. Figure 4 shows the comparison of the modeled and measured mixing ratios of these four gases. Looking at Fig. 4a we see that from midnight to midday, the model reproduces the measurements of $\mathrm{CO}$ quite well when the air masses originate from the $\mathrm{E}$ or SW with excellent agreement in absolute values as well as the general trends. Once the RML reaches the measurement site, however, the measured $\mathrm{CO}$ exceeds the concentration from the model by $50-80 \%$ in the air from the SW and E, respectively. The CO predicted by the model in the WNW air mass overestimates the CO by an average of ca. $0.05 \mathrm{ppm}$ throughout the day, with the exception of one hour at 14:00 when the measurements spike and exceed the model by $80 \%$. It has been observed previously (Baumgardner et al., 2009) that measured $\mathrm{CN}$ concentrations are typically well correlated with the $\mathrm{CO}$ mixing ratio at the research site. Comparing Figs. 2 and $4 \mathrm{a}$, the $\mathrm{CN}$ and measured $\mathrm{CO}$ begin to increase as the RML approaches the altitude of the research site and reach their maximum values at the same time. This occurs between
11:00 and 12:00 in the E and WNW air masses and between 13:00 and 14:00 in the SW case. The secondary peaks that are prominent in the measured $\mathrm{CO}$ are not as sharp in the trends of $\mathrm{CN}$ but inflections are still noticeable. These correlations in the measured $\mathrm{CN}$ and $\mathrm{CO}$ imply that the positive differences between the measured and modeled $\mathrm{CO}$ are not a result of $\mathrm{CO}$ that is being produced locally from the VOCs emitted from the trees, but are more likely due to an underestimate of the amount of $\mathrm{CO}$ being produced upwind of the research site (e.g. strength of direct sources may be underestimated) or an overestimate of the amount of dilution by mixing. It is important to note, however, that the average differences between the model and observations are smaller than the natural variability when air masses are from the WNW and E. On the other hand, although the differences are larger than the natural variability in the SW case, the trends are well represented by the model as seen in the correlation coefficient that is significant at the 0.001 level.

As observed in Fig. 4b and Table 3, the model simulations of $\mathrm{SO}_{2}$ do not correlate very well with the measurements and only in the easterly case is the average difference smaller than 
the natural variability. The $\mathrm{SO}_{2}$ emissions from Popocatepetl parameterized in the model vary from day to day corresponding to measurements made by Grutter et al (2008) and were greatest on 18 and 19 March when the air masses were from the SW. This is the source of the modeled $\mathrm{SO}_{2}$, seen in Fig. 4b, that is much higher than was measured. The significance of these differences is questionable, due to the resolution of the model that produces a wider plume of $\mathrm{SO}_{2}$ from the volcano than is actually emitted, i.e. although the volcano is a point source, in the model it is distributed over a $3 \mathrm{~km}$ by $3 \mathrm{~km}$ grid. In addition, the grid resolution of the topography in the model places the altitude of the emissions from the volcano several hundred meters lower than the actual peak of the volcano. This leads to more $\mathrm{SO}_{2}$ at a lower altitude than is actually the case.

The $\mathrm{O}_{3}$ is underestimated by the model throughout the $24 \mathrm{~h}$ period regardless of the air mass origin (Fig. 4c), although the average difference in the E case is smaller than the natural variability. When the model results are shifted two hours later with respect to the measurements the correlations are all positive and significant at the $P<0.01$ level (Table 3 ), indicating good agreement in the diurnal trends even though the absolute values are on average more than $0.02 \mathrm{ppm}$ lower than observed. The differences between the model and measurements are possibly due to an inadequate representation of $\mathrm{O}_{3}$ precursors (e.g. biogenic $\mathrm{VOC}$ ) in the emissions inventory, an underestimate of the continuing, photochemical production of $\mathrm{O}_{3}$, as was seen by Tie et al. (2009), or overestimation of the dilution by mixing as we observed in comparisons of the measured and modeled CO. It may be that the $25 \%$ difference between the measurements and model results, in the morning before the RML arrives at Altzomoni, is a result of an underestimate of photochemical production since Tie et al. (2009) observed a similar discrepancy. Once the RML is above the research site, however, the $50-80 \%$ difference is similar to the differences seen in the CO comparisons, leading us to conclude that the model is entraining free tropospheric air too rapidly.

The majority of acyl peroxy nitrates (APN) are composed of PAN and PPN and their principal loss mechanism is via thermal decomposition (Seinfeld and Pandis, 2006). To compare the modeled APN with the measurements, the PAN and PPN observations were lumped together. The comparisons (Fig. 4d) show that the model reproduces the measurements extremely well in the air masses with origin from the SW. The simulations and measurements have a correlation coefficient of 0.95 and average error of only $0.06 \mathrm{ppb}$ after shifting the simulations by one hour later than the measurements. For all cases the average difference between the simulations and observations is less than the calculated natural variability. The trends of the simulations and observations, in easterly air masses, are in good agreement in the morning from midnight until 13:00, then again in the late afternoon and evening after 17:00. The model overestimates APN during these time periods but follows a similar diurnal tendency. The model also over-predicts APN in the WNW air masses from midnight to 13:00 and, unlike the simulations for E and SW air masses, where APN decreases in the evening, the model keeps increasing APN. The rapid increase in APN around midday, not reproduced by the model, follows the same trend as was seen in the measured CO.

\section{Aerosol particle mass size distributions}

The size distributions of the mass concentrations of the sulfate, nitrate, ammonium and organic matter ions were averaged hourly and grouped by air mass origin over the same periods as previously discussed for the meteorological and trace gas measurements. The size spectra from the simulations were also grouped and averaged over these same periods. The AMS measures the vacuum, aerodynamic diameter of the particles, whereas the diameter reported from the WRF-Chem model is geometric. Hence, the size scales of the AMS spectra are converted to geometric diameter using a density of $1.8 \mathrm{~g} \mathrm{~cm}^{-3}$ for the sulfate, nitrate and ammonium particles and $1.4 \mathrm{~g} \mathrm{~cm}^{-3}$ for organic matter (Barnard et al., 2010). Figures 6-9 show three time periods chosen to represent the evolution of the size distributions: (1) 11:00 when the RML is just arriving at Altzomoni, (2) 14:00 when the maximum concentration of gases and particles is observed and (3) 17:00 when these concentrations are decreasing.

In the following discussion we focus specifically on the time evolution of three features of the particle size distributions (PSD): (1) the mass concentration of particles less than $0.1 \mu \mathrm{m}$, (2) the diameter and concentration of the peak in the accumulation mode of the PSD and (3) the general shape of the PSD with respect to deviation from log normality. The interest in the concentration of small particles is related to observing if either the model or the measurements show any new particle formation. Changes in the size and concentration of the accumulation mode of the PSDs provide information about growth of the particles by condensation and coagulation, as do changes in the overall shape of the spectra. As was previously described in Sect. 2.2, the model provides information on the size spectra via the concentrations and diameters of the Aiken and accumulation modes assuming a log normal probability distribution with a constant standard deviation for each mode. The size spectra shown in the figures are calculated from the sum of the two, overlapping log normal distributions.

\subsubsection{Partitioning of inorganic and organic compounds}

Prior to discussing the time evolution of the PSDs, we put these into context by comparing the average, bulk concentrations that were measured and simulated for the three cases. The mass concentrations of sulfate, nitrate, ammonium and organic ions, measured with the AMS and simulated with the model, were averaged over the three periods related to the air 

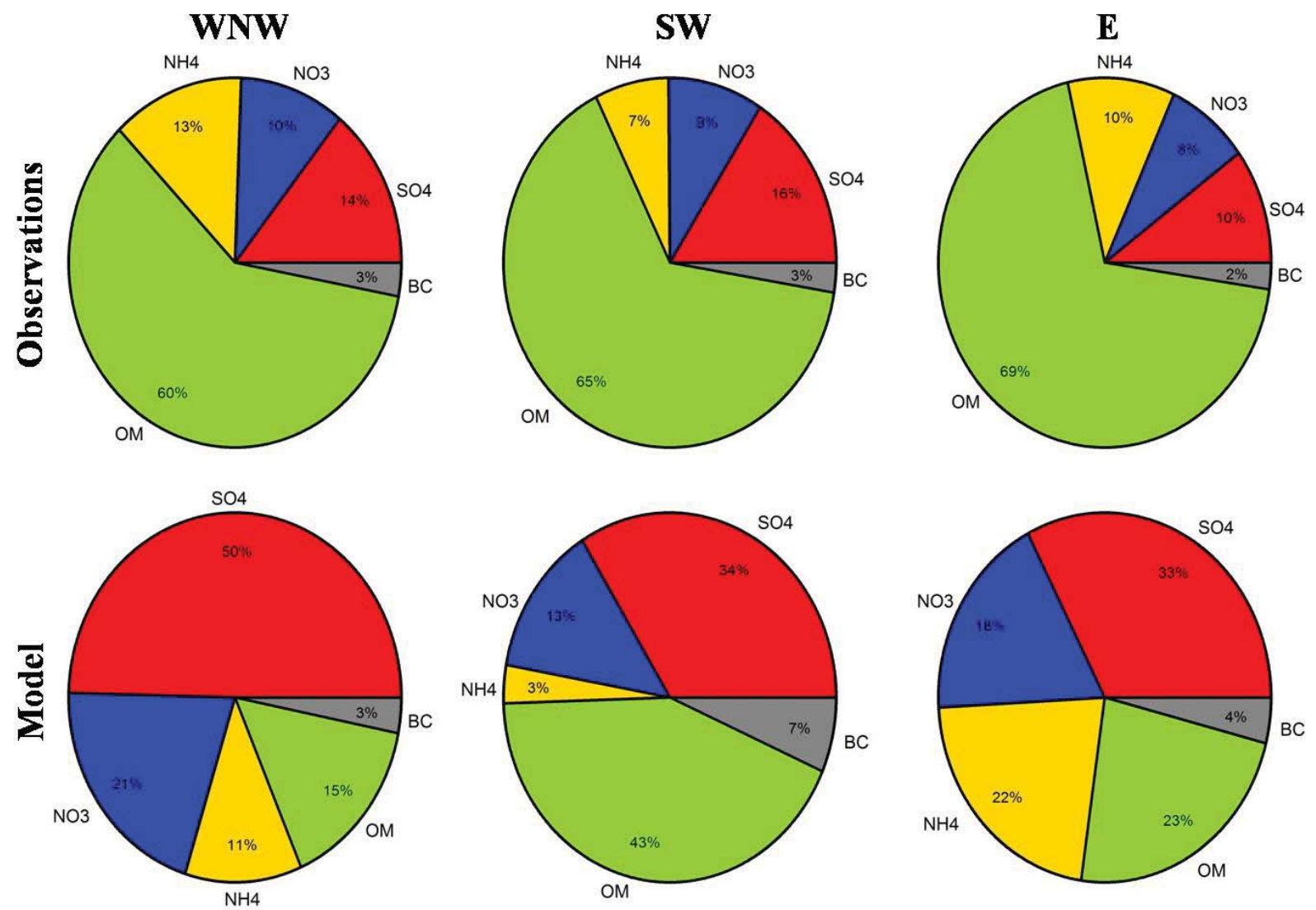

Fig. 5. These diagrams show how the inorganic and organic compounds measured with the AMS and simulated in the model are petitioned with respect to the origin of the air masses.

mass origins and partitioned according to fraction of the total aerosol mass. Figure 5 shows the comparison between the observed and modeled partitioning. Whereas the measurements show that the partitioning, on average, changes very little with respect to the air mass origin, the same partitioning by the model changes significantly, depending on the origin of the air mass. The simulated organic matter (OM) in particular is more than a factor of two higher in the SW air masses than in the WNW and E. In all three cases, the OM that is simulated is a much smaller fraction of the total mass while the fraction of modeled sulfate is more than a factor of two higher than was observed. The over abundance of simulated sulfate with respect to the observations is somewhat understandable for the case of SW air masses, where the simulated $\mathrm{SO}_{2}$ is well in excess of what is observed, leading to excess sulfate production. For the case of WNW and $\mathrm{E}$ air mass, where observed and modeled $\mathrm{SO}_{2}$ concentrations are very similar, the excess sulfate seen in the model is less understandable but will be further explored below in the discussion of PSDs.

\subsubsection{Evidence for new particle formation}

The conditions necessary for new particle formation are (1) high vapor pressure of precursor gases and (2) lack of existing particle surface area to which the precursor gas would diffuse and condense in preference to nucleating new particles. Given the amount of time that the RBL is developing prior to its arrival at the measurement site, it is likely that any new particle formation would have occurred before the particle properties are measured at the measurement site. Evidence might be found, however, in the simulated and observed PSDs by looking for signs of these new particles in the sizes $<100 \mathrm{~nm}$ where the Aitken or nucleation mode is found.

Figures 6-9 represent PSDs of the sulfate, nitrate, ammonium and organic ions for three different time periods, three air mass origins and from the measurements and the model. Note that the three PSDs are drawn with different scales on the ordinate axis because of the range in values predicted by the model.

Examining these figures, regardless of the origin of the air mass or composition, we see that the measured distributions (red curves) are generally monomodal, log normal in shape 


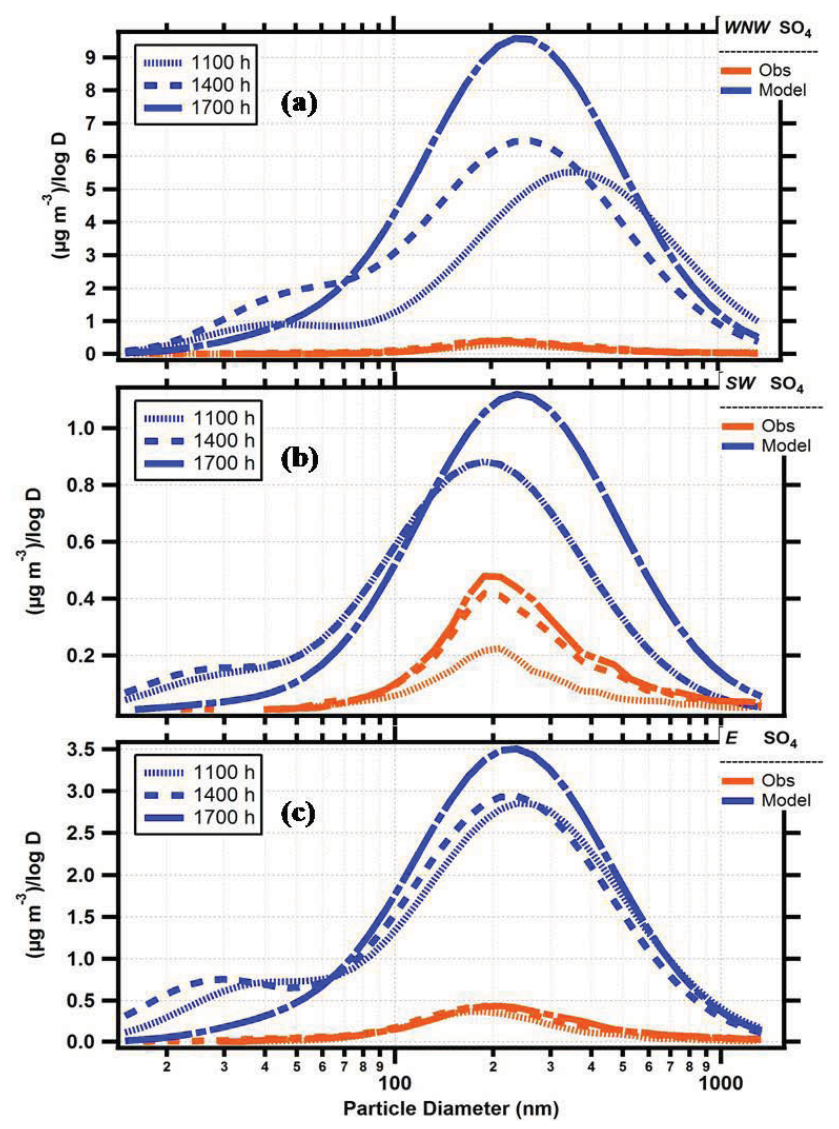

Fig. 6. The average mass concentrations of sulfate as a function of size, simulated by the model (blue lines) and measured with the AMS (green lines), are compared for three time periods when air originates from (a) the WNW, (b) SW and (c) E.

(Gaussian on a logarithmic scale) with their peaks falling in the size range of the accumulation mode. This suggests that had there been any new primary or secondary particle formation, sufficient time had passed such that they had grown to larger sizes by condensation and coagulation. The exception to this conclusion is perhaps found in the PSDs of nitrate (Fig. 8) and OM (Fig. 9). In WNW air, at 11:00 and 14:00, in SW air at 14:00 and 17:00 and in easterly air, at 17:00, there are inflections in the PSDs of nitrate at diameters less than $100 \mathrm{~nm}$ that suggest a mode of small particles that have yet to grow into the accumulation size range (Fig. 8). Likewise in Fig. 9 we see slight inflections in PSDs of OM measured in WNW and easterly air masses at 14:00 and at 17:00

The simulations (blue curves) tend to produce more pronounced inflections in the PSDs at sizes below $100 \mathrm{~nm}$, but only for the inorganic ions and at 11:00 and 14:00. Close to the source the model generates the initial, double log normal PSD by putting $20 \%$ and $80 \%$ of the primary emitted mass in the Aitken and accumulation modes, respectively. Secondary particles are formed with sizes in the Aitken mode by homogeneous nucleation in the water-sulfuric acid system as

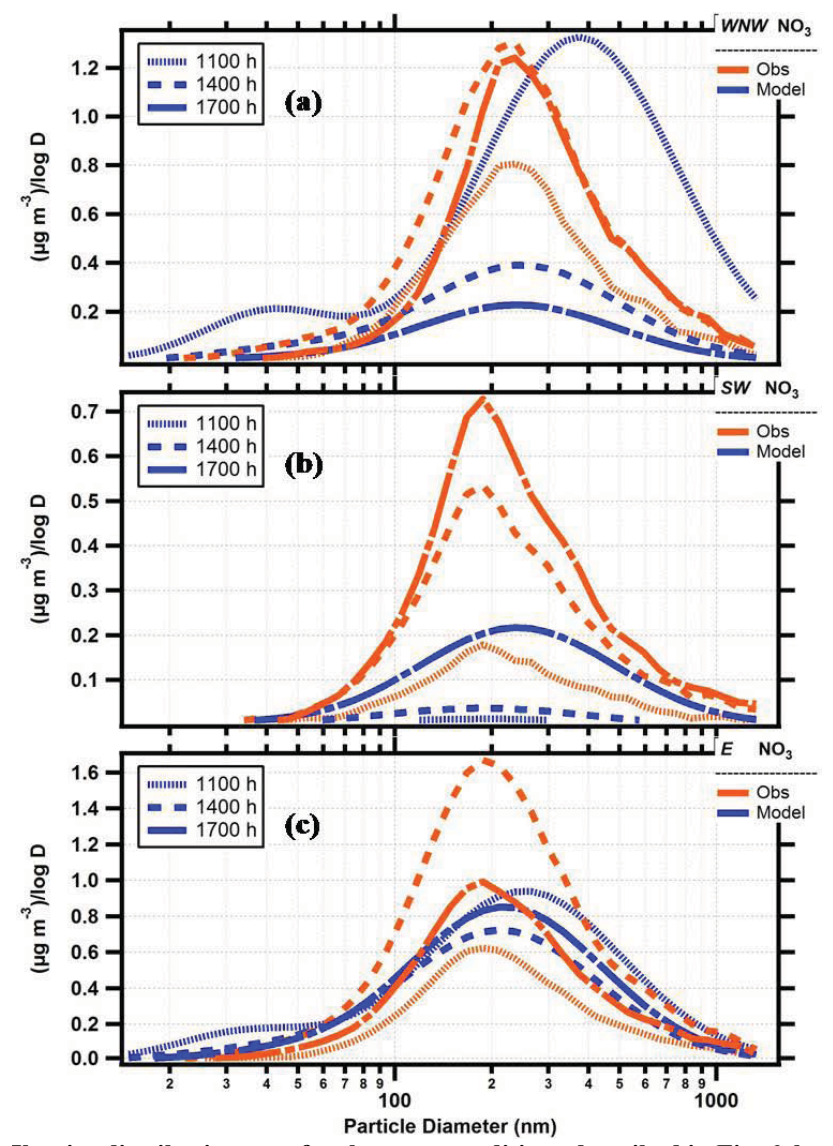

Fig. 7. The size distributions are for the same conditions described in Fig. 5, but for nitrate.

formulated by Wexler et al. (1994). This process only occurs when a critical concentration of sulfuric acid is exceeded. This critical concentration is a function of the temperature and relative humidity. The primary particles from emission and secondary particles from gas to particle conversion are both distributed in the Aitken mode with a median diameter of $10 \mathrm{~nm}$.

Figure 6 shows that the simulated PSDs of sulfate all have a small particle mode that forms at 11:00 and 14:00, but never at 17:00, regardless of the origin of the air mass. The only difference is that the mode in the WNW air masses falls near $40 \mathrm{~nm}$ and in the SW and E air masses it is found between 20 and $30 \mathrm{~nm}$. Hence, as will be discussed more below, the particles are newly formed sometime before 11:00 and have grown to larger sizes by 11:00 and 14:00 but the majority of the particles smaller than $100 \mathrm{~nm}$ have grown into the accumulation mode by 17:00.

As seen in Fig. 7, the simulated PSDs for nitrates have a small particle mode only at 11:00 when air is from the WNW and $\mathrm{E}$. The model does not have a mechanism for producing nitrate via homogeneous nucleation. Hence the particles in the Aitken mode were formed during primary emissions 


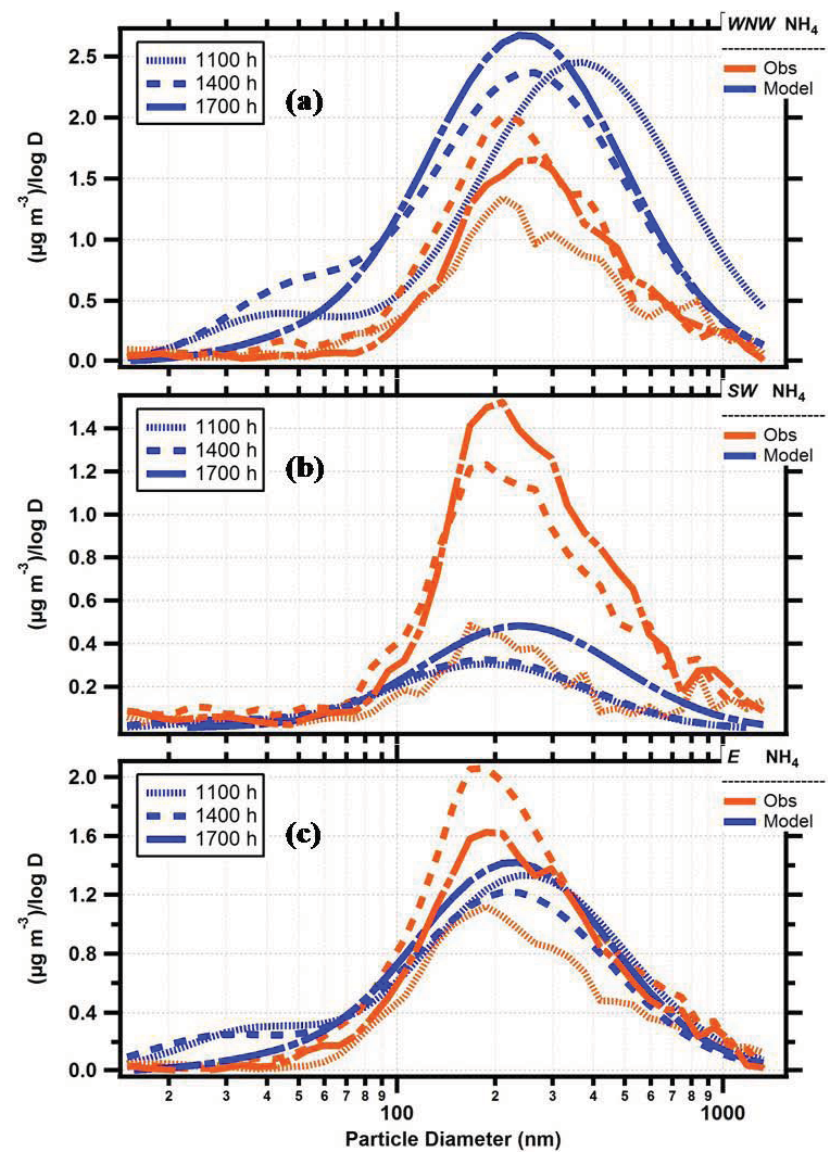

Fig. 8. The size distributions are for the same conditions described in Fig. 5, but for ammonium.

and most have grown by condensation into the accumulation mode by 14:00.

A similar behavior is seen in the ammonium PSDs (Fig. 8) except there are small particle modes seen at 11:00 and 14:00, similar to what was seen with the sulfate PSDs. As was seen in Fig. 5, a large fraction of the simulated mass is found in sulfate particles, most of which is in Ammonium sulfate. hence, the PSDs of the ammonium ions will look very similar to those for sulfate.

For the case of OM (Fig. 9), the modeled PSDs only have a small particle mode for air at 14:00 from the SW. Just as with the inorganic ions, the model created an initial mode with a median diameter at $10 \mathrm{~nm}$ from the primary emissions. The results displayed in Fig. 9, however, indicate that the majority of these particles have grown to larger sizes, into the accumulation mode, by 11:00.

\subsubsection{Evidence for particle growth}

In air masses close to emission sources, the measured PSDs are always multimodal with at least peaks in the Aitken and accumulation modes (e.g. Smith et al., 2008). As mentioned in the previous section, the lack of a small particle mode in the observations indicates that the new particles that formed from primary emissions or from secondary gas to particle conversions have already grown to larger sizes by the time they were measured at Altzomoni. The particles in the Aitken mode that are simulated also grow but not as quickly since there is still evidence for these particles in the PSD at sizes smaller than $100 \mathrm{~nm}$.

When we examine the accumulation mode in the measured PSDs, there is no noticeable change as a function of time in the diameter where the peak falls in this mode, i.e. for any given inorganic or OM ion PSD, and any air mass case, the peaks at 11:00, 14:00 and 17:00 have approximately the same average diameter. All that changes is the concentration at the peak. As will be discussed below, changes in concentration without a change in the mean diameter indicate that the majority of particle growth has occurred prior to the arrival of the air mass at the research site and all that is changing the mass concentration is the amount of dilution as the boundary layer grows.

As previously described, the model allocates $20 \%$ of primary emitted particle mass to the Aitken mode and $80 \%$ to the accumulation mode. The median diameter of the Aitken mode is fixed at $10 \mathrm{~nm}$ and for the accumulation mode the median diameter is set at $70 \mathrm{~nm}$. As can be seen in Figs. 69 , for all ions and air mass origins, the accumulation modes have peaks that fall between 180 and $300 \mathrm{~nm}$. Hence, the particles that were initially centered at $70 \mathrm{~nm}$ have grown by about a factor of three. As with the measurements, in some cases the median diameter of the accumulation mode remains approximately constant as the day proceeds from 11:00 to 17:00, such as the PSD of sulfate in air masses from the East (Fig. 6c). More often, however, there is a decrease in the median diameter from 11:00 to 17:00 as illustrated in Figs. 6a, $7 \mathrm{a}, 8 \mathrm{a}$ and $9 \mathrm{a}$. This behavior is discussed in greater detail below.

\subsubsection{Evolution of particle shape}

Numerous studies have shown that ambient aerosol size distributions will generally have a log normal shape due to the underlying processes that drive their evolution. Hence, the WRF-Chem model simulates the PSDs with the sum of two log normal distributions and the processes of condensation and coagulations will move the particle sizes to larger diameters without changing the general log normal shape, other than to modify its width and modal diameter. This is seen in the modeled PSDs drawn in Figs. 6-9, particularly in the accumulation mode where the mass is distributed symmetrically either side of the median diameter.

The measurements also have the shape of a log normal distribution in many of the figures, e.g. 6a and c, 7a and c, 9a,b,c. There are exceptions, however, where the PSD is skewed to the right, such as seen in Figs. $6 \mathrm{~b}, 7 \mathrm{~b}$ and $8 \mathrm{a}, \mathrm{b}, \mathrm{c}$. All of the ammonium PSDs show signs of an additional inflection point to the right of the peak diameter. This suggests 


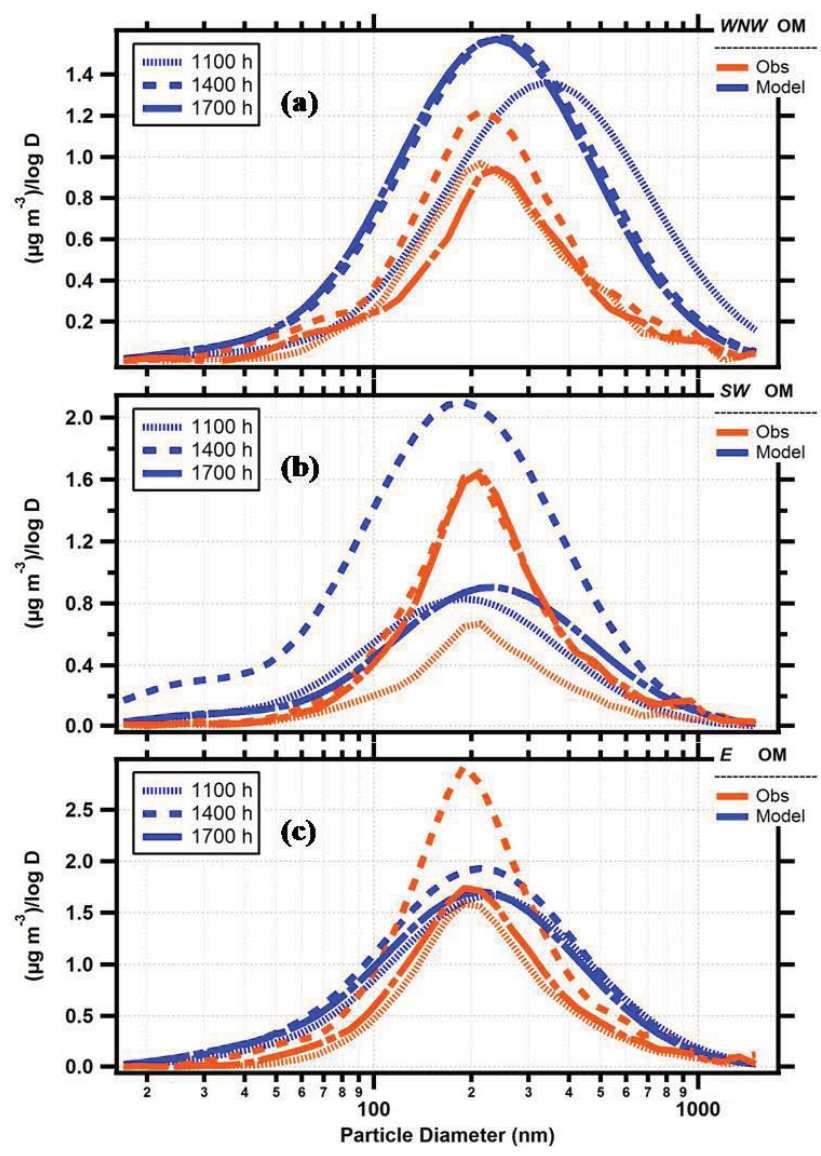

Fig. 9. The size distributions are for the same conditions described in Fig. 5, but for organic material.

that some fraction of the particles with the ammonium ion, e.g. ammonium sulfate and ammonium nitrate, are growing to larger sizes. This seems particularly pronounced in the air masses from the SW in the sulfate, nitrate and ammonium PSDs (Figs. 6b, 7b and 8a).

With respect to the agreement between the modeled and measured PSDs, the nitrate PSDs compare very well at 14:00 when air is from the E (Fig. 7c). Likewise, when comparing ammonium ions (Fig. 8a-c) we observe that there is good agreement between the model and the measurements in the easterly air masses at 14:00 (Fig. 8c), similar to what was seen in the comparison of nitrate PSDs. The measured peak concentration is slightly higher and diameter a little smaller.

The measured PSDs of organic matter, shown in Fig. 8a-c, all reach their maximum peak concentrations at 14:00, with very little shifts in the peak diameter regardless of air mass origin.

\section{Discussion}

As seen in the summary of the comparisons (Table III), the daily trends from the model and measurements, as measured by the correlation coefficients, are often in good agreement, using a confidence level of $\mathrm{Pc}<0.01$ as the criterion for a statistically significant value. The temperature and water vapor mixing rations were highly correlated, regardless of air mass origin, as was the ozone. The $\mathrm{CO}$ was very well correlated prior to the arrival of the RML but the significant underestimation by the model after that time causes the correlation coefficients to decrease. Of the 18 comparisons (six parameters and three different air mass directions) 12 were statistically significant. Most of these were reached when the average time series from the model is shifted by one or two hours ahead or behind the observations. For example the best correlations for $\mathrm{O}_{3}$ were obtained when the modeled concentrations were shifted two hours later for the WNW and E air masses and one hour later for southwesterly air. The need to shift the model results in time suggests that the $\mathrm{BL}$ is growing too rapidly in the model.

In Sect. 3.2 the trends in the modeled BL were compared with the onset of increases in the $\mathrm{CN}$ concentration. It was observed that the $\mathrm{CN}$ concentration generally began increasing at the time when the depth of the BL was close to the elevation of the research site. Taking a closer look at Fig. 2, we see that the really sharp increases in $\mathrm{CN}$ don't occur in the air originating from the WNW and E (Fig. 2a and c) until two hours after the BL is at the site. Similarly in southwesterly air the increase in $\mathrm{CN}$ occurs an hour after the arrival of the BL (Fig. 2b). These time lags are the same as those required to produce correlated $\mathrm{O}_{3}$ between the model and the measurements and reinforces our conclusion that the RML is growing too rapidly in the simulations.

Prior to the arrival of the RML at Altzomoni, we observe that the model underestimates the $\mathrm{O}_{3}$ with respect to the measurements by approximately $25 \%$ and then by $50-80 \%$ afterwards. In Sect. 3.3 we suggest that the $25 \%$ difference is a result of the continuing photochemical production of $\mathrm{O}_{3}$ that is not taken into account in the model, as concluded by Tie et al. (2009). The much larger difference in $\mathrm{O}_{3}$ after the RML reaches the research site was also observed in the comparison of $\mathrm{CO}$ and is further evidence that the simulated $\mathrm{BL}$ growth is overly vigorous. Turbulence generated by solar heating entrains free tropospheric air as the BL grows and leads to mixing and dilution of the gases and particles in the BL. Figure 10 illustrates this process with simulated vertical profiles of $\mathrm{CO}$ (Fig. 10a) and $\mathrm{O}_{3}$ (Fig. 10b) at the three sites shown in Fig. 1 and whose trends in the BL depth were presented in Fig. 2. The time periods selected are 11:00, 14:00 and 18:00 to correspond to the average time at which the RML arrives at Altzomoni, time of maximum CN and time when the RML is beginning to collapse, respectively. The horizontal lines, (black, red and green for cases of air from the WNW, SE and $\mathrm{E}$, respectively), drawn at the pressure altitude of Altzomoni, represent the maximum $\mathrm{CO}$ (Fig. 10a) and $\mathrm{O}_{3}$ (Fig. 10b). The modeled maximum value is given by the diamond on the left of the line and the measured value is shown as a solid circle 
on the line. An arrow designates that the measured value is greater than the maximum on the scale of the figure.

Although the absolute magnitudes of $\mathrm{CO}$ shown on Fig. 10a are different at the three sites, the trends are similar. At 11:00 the CO is the largest at the surface and smallest at the elevation of the research site. By 14:00 the CO has mixed upwards, decreasing the concentration at the surface but increasing it at the research site. The trends in Mexico City (WNW) and Texmelucan (E) are similar, i.e. the maximum in $\mathrm{CO}$ at the same pressure level of Altzomoni $(630 \mathrm{mb})$ occurs at 14:00 then by 18:00 the continuing dilution brings down the average concentration. The maximum in $\mathrm{CO}$ when air is from the SW (Cuautla) occurs at 18:00 because Cuautla is $1000 \mathrm{~m}$ lower in altitude than Mexico City and Texmelucan; hence, it takes longer for the emissions from that area to reach the research site. The model results coincide with the measured trends in $\mathrm{CO}$ and $\mathrm{CN}$ that show the maxima occurring later and also remaining high until 20:00 (Figs. 2b and 4a). Comparing these profiles in Fig. 10 with the maximum modeled and measured $\mathrm{CO}$ at Altzomoni, we see that in the WNW air masses, there has been a 13:1 dilution in the maximum $\mathrm{CO}$ that is at $630 \mathrm{mb}$ over Mexico City, i.e. the maximum $\mathrm{CO}$ concentration upwind at the surface at 11:00 was $2.0 \mathrm{ppm}$ but the maximum measured at Altzomoni was $0.15 \mathrm{ppm}$ When looking at the results from Cuautla the modeled $\mathrm{CO}$ at Altzomoni is $20 \%$ greater than the $\mathrm{CO}$ upwind at the same level over Cuautla. This means that the CO continues to be mixed upwards from the surface; however, given that the measured $\mathrm{CO}$ was $30 \%$ larger than was simulated, it implies that the CO is over-diluted in the model. A different situation occurs in the easterly air masses where the $\mathrm{CO}$ from the model is the same at the research site as at the same level upwind at Texmelucan; however, the measured $\mathrm{CO}$ is $80 \%$ larger, almost the same concentration as found at the surface at Texmelucan at 11:00. This suggests that not only has there been too much dilution in the model, but the emission strength of $\mathrm{CO}$ is also likely underestimated.

Figure 10b shows that the $\mathrm{O}_{3}$ profiles are much more vertical from the surface to the altitude of Altzomoni at 11:00 than seen in the $\mathrm{CO}$ profiles. This is a result of vertical mixing and photochemical production of new $\mathrm{O}_{3}$. The maximum concentration is reached at 14:00, at all three sites, decreasing by 18:00; however, the trends are different with respect to the magnitude of the decrease. In the WNW air masses represented by the Mexico City profiles the concentration of $\mathrm{O}_{3}$ decreases to a value halfway between the 11:00 and 14:00 concentrations. This trend is reflected in the measured $\mathrm{O}_{3}$ in the WNW air (Fig. 4c), that changes from 0.06 to 0.09 to $0.07 \mathrm{ppm}$ over these same time periods. When air arrives from the SW, as represented by the Cuautla vertical profile (Fig. 10b), the $\mathrm{O}_{3}$ concentration at 18:00 returns to its 11:00 value. This trend also is reflected in the measurements. Only the profiles of air from the E differ from the trends that were measured. In this case the 18:00 concentration falls between the 11:00 and 14:00 values but the measured $\mathrm{O}_{3}$ at 18:00

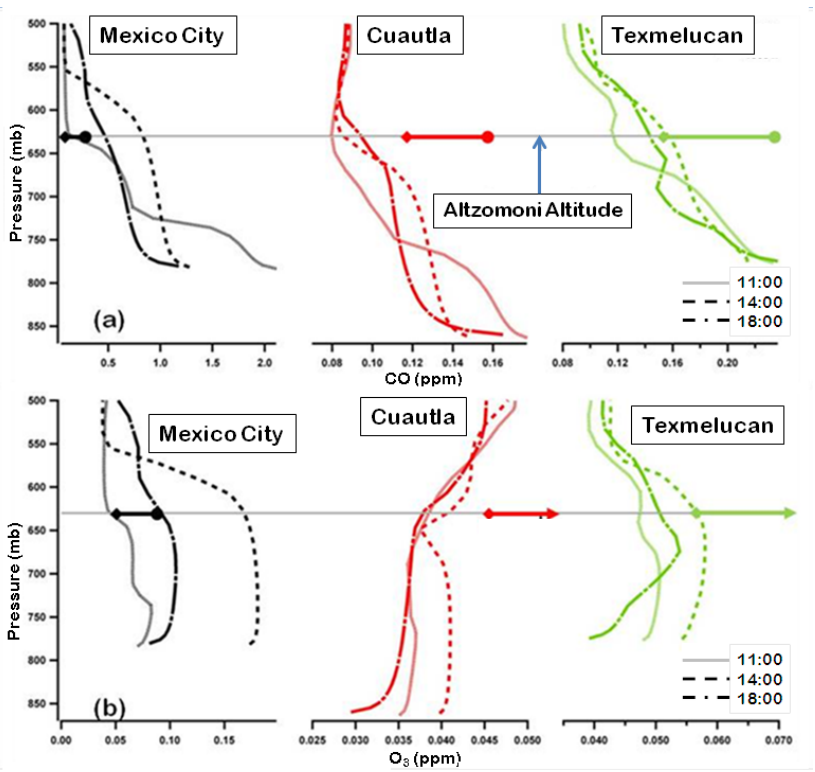

Fig. 10. The simulated vertical profiles displayed here are for (a) $\mathrm{CO}$ and (b) $\mathrm{O}_{3}$ concentrations at three locations upwind of Altzomoni when the winds are from the WNW (black curves, Mexico City), SW (red curves, Cuautla) and E (green curves, Texmelucan) at three time periods. The 1100 periods (light solid curves) are when the RML is arriving at Altzomoni, 1400 periods (dark dashed curves) are when the $\mathrm{CO}$ and $\mathrm{O}_{3}$ are approximately maxima and 1800 periods (dark solid curves) are when the RML is beginning to collapse. The horizontal, solid bars at the pressure level of Altzomoni connect the simulated (diamond) and measured (solid circle) concentrations at Altzomoni. The arrow signifies that the measured concentration is larger than the maximum on the scale.

is approximately what it was at 14:00. In comparison with the maximum modeled and measured $\mathrm{O}_{3}$ at the research site (horizontal bars, Fig. 10b) we find that the $\mathrm{O}_{3}$ is a factor of three lower at Altzomoni than at the same pressure altitude over Mexico City, i.e. continuing photochemical production of $\mathrm{O}_{3}$ has been offset by dilution. The measured $\mathrm{O}_{3}$, however, is almost a factor of two larger than the simulation. This reflects either more actual production of $\mathrm{O}_{3}$ or less dilution than predicted. The comparisons of model and measurements at the research site in SW air, in relation to the simulated vertical profiles at Cuautla, shows that the photochemical production of $\mathrm{O}_{3}$ by the model overcomes the dilution by mixing as the modeled concentration downwind of Cuautla is slightly larger than the concentration upwind.

The measured $\mathrm{O}_{3}$ under conditions of southwesterly winds, is $0.15 \mathrm{ppm}$, off the scale in this figure, suggesting that there is much more $\mathrm{O}_{3}$ actually being produced than predicted. The same is seen in the comparisons in easterly air masses where the measured maximum $\mathrm{O}_{3}$ at Altzomoni is $0.11 \mathrm{ppm}$, twice what is predicted.

When comparing the model predictions and AMS measurements of the PSDs, we note that the maximum geometric 
size that can be sampled with approximately $100 \%$ efficiency is about $600 \mathrm{~nm}$. This is a result of operating at $630 \mathrm{mb}$, the average pressure level of Altzomoni. As seen in figures 6-9, there is mass that is detected beyond this size but the uncertainty due to the decreased aspiration efficiency is much larger and we refrain from placing any significance on differences between the model and the measurements in this size range.

The analysis of PSDs measured as the RML rose above the research site and their comparison with simulations produced a number of interesting insights with respect to the evolution of aerosol particles downwind of the major emission sources. The first of these was the observation that the measured size spectra were always log normally distributed with a single mode centered at a geometric diameter of $200 \pm 20 \mathrm{~nm}$, regardless of the time of day, origin of the air mass or chemical composition. Differences were only reflected by changes in the maximum concentration of the peak and area under the curve. From 11:00 to 17:00 there was rarely any indication of particle change in size by condensation, coagulation or evaporation. The lack of any mode in the small particle size range $(<100 \mathrm{~nm})$ suggests that by the time the RML had reached the research site, most of the particles in the Aiken mode had grown into the accumulation mode and there was no formation of new particles. Kleinman et al. (2009) made a similar observation from air borne measurements downwind of Mexico City. In their studies, they evaluated the size distribution as a function of photochemical age that was defined as the negative logarithm of the concentration of $\mathrm{NO}_{\mathrm{x}}$ to $\mathrm{NO}_{\mathrm{y}}$ that has a value of 1.0 after approximately $8 \mathrm{~h}$ of processing. Baumgardner et al. (2009) showed measurements of CO and $\mathrm{O}_{3}$ made in Mexico City and Altzomoni that showed that on average air from Mexico City, under conditions of WNW circulation, reach Altzomoni in approximately $6 \mathrm{~h}$. This corresponds to a photochemical age of around $0.7-0.8$. As we didn't have measurements of $\mathrm{NO}_{\mathrm{x}}$ and $\mathrm{NO}_{\mathrm{y}}$, we are unable to compute a comparable photochemical age to directly compare with that which was reported by Kleinman et al. (2009). Nevertheless, these investigators reported measurements of the PSDs of organic matter from an AMS on an aircraft. The modal diameter of the PSDS in the afternoon was nearly the same as measured at Altzomoni, i.e. $200 \mathrm{~nm}$, and shapes were independent of the photochemical age. One difference was that whereas our measurements at Altzomoni show no evidence of a small particle mode, some of the PSDs from the aircraft measurements showed evidence of such a mode in the photochemically young air masses. This was not seen in the PSD in air with a photochemical age between 0.8 and 1 .

The predicted PSDs showed larger shifts in the modal diameter with time of the day, particularly for the sulfate, nitrate and Ammonium where the mode tends to shift from close to $400 \mathrm{~nm}$ at $11: 00$ moving towards $200 \mathrm{~nm}$ at 17:00, i.e. very close to what is observed. This decrease in modal diameter is accompanied by an increase in the maximum concentration. The reason for the decrease in the modal diame- ter is that the model predicts another peak in the Aiken mode such that these particles grow by condensation and coagulation into the accumulation mode, shifting the modal diameter to smaller sizes. The measurements indicate that the majority of mass in the Aiken mode has already shifted into the accumulation mode before the air masses have reached the research site.

The large difference between the modeled and measured sulfate is due to two factors: an overestimate of the $\mathrm{SO}_{2}$ and water vapor mixing ratio and the way that the model handles the inorganic chemistry. An overabundance of $\mathrm{SO}_{2}$ and water vapor will lead to the production of too much sulfate from aqueous chemistry. Secondly, the chemical system considered in MADE, the module that simulate the inorganic chemistry, is restricted to sulfate, nitrate, ammonium and water components in the aerosol phase. The sulfate formed in the model by oxidation of $\mathrm{SO}_{2}$ in the gas-phase is neutralized irreversibly by ammonia to produce ammonium sulfate. Any excess ammonia reacts with nitric acid in the model resulting in the reversible formation of ammonium nitrate aerosol. Hence, we see from figures $8 \mathrm{a}$ and $\mathrm{b}$ that the simulated sulfate exceeds that which is measured while the measured nitrate exceeds the simulated concentrations. The exception was in the easterly air masses where even though the sulfate is greatly overestimated, at 17:00 the modeled and measured concentrations are in close correspondence. This suggests that even though the sulfate is over predicted, by the time all the $\mathrm{SO}_{2}$ had been removed there remained enough ammonia left to produce the ammonium nitrate. This also indicated that the model was doing a good job of predicting the available nitric acid.

The differences between the modeled and measured PSDs of OM vary with air mass origin and are related to both the dynamics and the chemistry. One commonality is that there is little evidence of new particle formation or mass in the Aiken mode in either the measurements or the model results. Only at 14:00 in SW air masses does the model indicate that there are particles with significant mass in this mode that disappears by 17:00. In addition, with the exception of WNW air masses, the modeled PSDs do not shift their peak diameters but only increase or decrease in maximum concentration. This matches the behavior of the measurements and is significant since it indicates that there is no longer any growth of the particles by 11:00 and any increases or decreases are a result of mixing processes.

The observation that both modeled and measured PSD are $\log$ normally distributed indicates that the use of the $\log$ normal distribution is justified in the model. Barnard et al. (2010) had reached the same conclusion when they evaluated the optical module of WRF-Chem using real chemical data. The WRF-Chem optical module take the multi-mode log normal PSDs, calculated from the chemical information to predict the optical coefficients. Barnard et al. (2010) found that when they compared measured optical data with simulated data using measured chemical concentrations in the 
optical module, the results were satisfactory. When the simulated chemistry was used in the optical module, there were large differences suggesting the modeled chemistry was the source of the error, not the log normal distributions.

\section{Summary and conclusions}

An evaluation of the fidelity of the WRF-Chem chemical transport model has been conducted using measurements taken during the MILAGRO campaign in the region of Mexico City in March, 2006. The evaluation compares the simulations of meteorology, selected trace gases and aerosol particle mass size distributions to those that were measured at a remote mountain site $60 \mathrm{~km}$ to the southeast of Mexico City for 10 days during the field campaign when there were no clouds or indications of local biomass burning. The comparisons were stratified by the history of the air masses over the $24 \mathrm{~h}$ before they arrived at the measurement site. Analysis of the wind fields derived from the North American Regional Reanalysis (NARR) at $650 \mathrm{mb}$ showed that air originated from the E, SW and WNW during 6, 2 and 2 of the 10 days, respectively. The comparisons were made after calculating diurnal averages, in one hour intervals, for the three cases. The metrics used to evaluate the predicted trends of the models in comparison with the measurements were the correlation coefficient and average difference between the simulated and measured values. The former metric indicates how well the daily trends are simulated while average differences help us assess possible biases.

The analysis shows that the trends in temperature, water vapor mixing ratio and $\mathrm{O}_{3}$ are significantly correlated $(P<0.01)$, after shifting the modeled data with respect to the measurements by one or two hours. The $\mathrm{CO}$ trends are also well represented by the model prior to when the RML reaches the measurement site of Altzomoni. After that time the measurements exceed the modeled concentrations by 50 $80 \%$. The APN concentrations are predicted very accurately in the cases when the air masses are from the WNW and SW but underestimated with respect to the measurements in air from the east, although the average trends are correlated.

Evaluation of the vertical profiles of the $\mathrm{CO}$ and $\mathrm{O}_{3}$ at three upwind locations indicate that the underestimation of simulated CO when the research site is in the RML is a result of overly vigorous entrainment and mixing of free tropospheric air by the model. The underestimate of the $\mathrm{O}_{3}$ is also related to over dilution, but there is also evidence that more $\mathrm{O}_{3}$ is being produced photochemically than predicted by the model.

The particle size distributions (PSD) of mass concentrations of sulfate, nitrate, ammonium and organic matter (OM) agree very well with respect to the geometric diameter of the peak in the $\log$ normal distributions that fell within $200 \pm 20 \mathrm{~nm}$ regardless of the origin of the air mass or its age when the measurement site was in the RML. The ma- jor differences were in the sulfate and nitrate PSDs where concentrations of sulfate are over predicted and nitrate under predicted by the model.

The fidelity of the model, validated by the measurements, is generally quite good with respect to the prediction of temperature, water vapor, $\mathrm{CO}, \mathrm{O}_{3}$, APN and PSDs of ammonium and, in some cases, OM. A better partitioning in the reactions of ammonia with $\mathrm{SO}_{2}$ and nitric acid is needed to minimize the overestimation of sulfate and underestimation of nitrate. Improvements are needed in how the model develops the thickness of the boundary layer and entrains and mixes with the free tropospheric air. The discrepancy in the modeled $\mathrm{O}_{3}$ and $\mathrm{OM}$ would probably be improved by a better emissions inventory of volatile organic compounds, although further investigation is needed to separate differences related to chemistry from those caused by dynamics. In addition, the $3 \mathrm{~km} \times 3 \mathrm{~km}$ resolution used in the modeled was not sufficient to resolve some of the smaller scale topographical features. This could contribute to observed differences in the meteorological parameters and phase lag in the diurnal cycles. Future work will add an additional nested grid at finer resolution centered on the research site.

The modeled and observed invariability of the shape of the PSDs and constant peak modal diameter suggest that after six hours of aging downwind of major sources of anthropogenic emissions, the aerosol population can be well represented by a single, log normal distribution with modal diameter of $200 \mathrm{~nm}$. This could greatly simplify parameterization in climate models although it is not known at this time if this invariance can be extended to other megacity regions.

Acknowledgements. The authors would like to thank the national park of Izta-Popo-Zoquiapan and its personnel for supporting the research at the Altzomoni measurement site and for assisting us in maintaining the equipment during the project. We would like to thank Armando Retama, director of the Red Automática de Monitoreo Atmosférico (RAMA) for providing the RAMA mobile van during the preliminary measurements in November 2005 and the measurements from RAMA in the city during March, 2006. We are grateful to TSI Inc, Mexico, for the loan of the Scanning Mobility Particle Sizer (SMPS) that was used during the project and to Lynn Russell, of Scripps Oceanographic Institute, for the loan of the AMS. This project was partially supported by PAPIIT grants \#IN-117403 IN-113306. The AMS measurements at Altzomoni were partially supported by a grant from the James S. McDonnell Foundation.

Edited by: L. Molina 


\section{References}

Ackermann, I. J., Hass, H., Memmesheimer, M., Ebel, A., Binkowski, F. S., and Shankar, U.: Modal aerosol dynamics model for Europe: Development and first applications, Atmos. Environ., 32, 2981-2999, 1998.

Aiken, A. C., Salcedo, D., Cubison, M. J., Huffman, J. A., DeCarlo, P. F., Ulbrich, I. M., Docherty, K. S., Sueper, D., Kimmel, J. R., Worsnop, D. R., Trimborn, A., Northway, M., Stone, E. A., Schauer, J. J., Volkamer, R., Fortner, E., de Foy, B., Wang, J., Laskin, A., Shutthanandan, V., Zheng, J., Zhang, R., Gaffney, J., Marley, N. A., Paredes-Miranda, G., Arnott, W. P., Molina, L. T., Sosa, G., and Jimenez, J. L.: Mexico City aerosol analysis during MILAGRO using high resolution aerosol mass spectrometry at the urban supersite (T0) - Part 1: Fine particle composition and organic source apportionment, Atmos. Chem. Phys. Discuss., 9, 8377-8427, doi:10.5194/acpd-9-8377-2009, 2009.

Barnard, J. C., Fast, J. D., Paredes-Miranda, G., Arnott, W. P., and Laskin, A.: Technical Note: Evaluation of the WRF-Chem "Aerosol Chemical to Aerosol Optical Properties" Module using data from the MILAGRO campaign, Atmos. Chem. Phys., 10, 7325-7340, doi:10.5194/acp-10-7325-2010, 2010.

Baumgardner D., Raga G. B., Kok G., Ogren J., Rosas I., Baez A., and Novakov T.: On the evolution of aerosol properties at a mountain site above Mexico City, J. Geophys. Res., 105, 22,24322,253, doi:10.1029/2000JD900299, 2000.

Baumgardner, D., Grutter, M., Allan, J., Ochoa, C., Rappenglueck, B., Russell, L. M., and Arnott, P.: Physical and chemical properties of the regional mixed layer of Mexico's Megapolis, Atmos. Chem. Phys., 9, 5711-5727, doi:10.5194/acp-9-5711-2009, 2009.

Bevington, P. R. and Robinson D. K.: Data reduction and error analysis for the physical sciences, 3rd edn., McGraw Hill Companies Inc., 2003.

Canagaratna M. R., Jayne J. T., Jimenez J. L., Allan J. D., Alfarra M. R., Zhang Q., Onasch T. B., Drewnick F., Coe H., Middlebrook A., Delia A., Williams L. R., Trimborn A. M., Northway M. J., Kolb C. E., Davidovits P., Worsnop D. R.: Chemical and microphysical characterization of ambient aerosols with the aerodyne aerosol mass spectrometer, Mass Spectrom. Rev., 26, 185-222, 2007.

Cross E. S., Slowik J. G., Davidovits P., Allan J. D., Worsnop D. R., Jayne J. T., Lewis D. K., Canagaratna M. and Onasch T. B: Laboratory and Ambient Particle Density Determinations using Light Scattering in Conjunction with Aerosol Mass Spectrometry, Aerosol Sci. Tech., 41, 4,343-359, 2007.

DeCarlo, P. F., Dunlea, E. J., Kimmel, J. R., Aiken, A. C., Sueper, D., Crounse, J., Wennberg, P. O., Emmons, L., Shinozuka, Y., Clarke, A., Zhou, J., Tomlinson, J., Collins, D. R., Knapp, D., Weinheimer, A. J., Montzka, D. D., Campos, T., and Jimenez, J. L.: Fast airborne aerosol size and chemistry measurements with the high resolution aerosol mass spectrometer during the MILAGRO Campaign, Atmos. Chem. Phys. Discuss., 7, 18269-18317, doi:10.5194/acpd-7-18269-2007, 2007.

Dominguez-Taylor, P., Ruiz-Suarez, L.G., Rosas-Perez, I., Hernandez-Solis, J.M., Steinbrecher, R.: Monoterpene and isoprene emissions from typical tree species in forests around Mexico City, Atmos. Environ., 41, 2780-2790, 2007.

Doran, J. C., Abbott, S., Archuleta, J., Bian, X., Chow, J., Coulter, R. L., de Wekker, S. F. J., Edgerton, S., Elliott, S., Fernandez, A.,
Fast, D. J., Hubbe, J. M., King, C., Langley, D., Leach, J., Lee, J. T., Martin, T. J., Martinez, D., Martinez, J. L., Mercado, G., Mora, V., Mulhearn, M., Pena, J. L., Petty, R., Porch, W., Russell, C., Salas, R., Shannon, J. D., Shaw, W. J., Sosa, G., Tellier, L., Templeman, B., Watson, J. G., White, R., Whiteman, C. D., and Wolfe, D.: The IMADA-AVER boundary-layer experiment in the Mexico City area, B. Am. Meteor. Soc., 79, 2497-2508, 1998.

Dunn, M. J., Jimenez, J. L., Baumgardner, D., Castro, T., McMurry, P. H. and Smith, J. N.: Measurements of Mexico City nanoparticle size distributions: Observations of new particle formation and growth, Geophys. Res. Lett., 31, L10102, doi:10.1029/2004GL019483, 2004.

Edgerton, S. A., Bian, X., Doran, J. C., Fast, J. D., Hubbe, J. M., Malone, E. L., Shaw, W. J., Whiteman, C. D., Zhong, S., Arriaga, J. L., Ortiz, E., Ruiz, M., Sosa, G., Vega, E., Limon, T., Guzman, F., Archuleta, J., Bossert, J. E., Elliot, S., Lee, J. T., McNair, L.A., Chow, J. C., Watson, J. G., Coulter, R. L., Doskey, P. V., Gaffney, J. S., Marley, N. A., Neff, W., and Petty, R.: Particulate Air pollution in Mexico City: A Collaborative Research Project, J. Air Waste Manag. Assoc., 49, 1221-1229, 1999.

Fast, J. and Zhong, S.: Meteorological factors associated with inhomogeneous ozone concentrations within the Mexico City basin, J. Geophys. Res., 103, 18927-18946, 1998.

Fast, J., Aiken, A. C., Allan, J., Alexander, L., Campos, T., Canagaratna, M. R., Chapman, E., DeCarlo, P. F., de Foy, B., Gaffney, J., de Gouw, J., Doran, J. C., Emmons, L., Hodzic, A., Herndon, S. C., Huey, G., Jayne, J. T., Jimenez, J. L., Kleinman, L., Kuster, W., Marley, N., Russell, L., Ochoa, C., Onasch, T. B., Pekour, M., Song, C., Ulbrich, I. M., Warneke, C., Welsh-Bon, D., Wiedinmyer, C., Worsnop, D. R., Yu, X.-Y., and Zaveri, R.: Evaluating simulated primary anthropogenic and biomass burning organic aerosols during MILAGRO: implications for assessing treatments of secondary organic aerosols, Atmos. Chem. Phys., 9, 6191-6215, doi:10.5194/acp-9-6191-2009, 2009.

Grell, G. A., Peckham, S. E., Schmitz, R., and McKeen, S. A., Frost, G., Skamarock, W. C., and Eder, B.: Fully coupled "online" chemistry within the WRF model, Atmos. Environ., 39, 6957-6976, 2005.

Grutter, M., Basaldud, R., Rivera, C., Harig, R., Junkerman, W., Caetano, E., and Delgado-Granados, H.: $\mathrm{SO}_{2}$ emissions from Popocatépetl volcano: emission rates and plume imaging using optical remote sensing techniques, Atmos. Chem. Phys., 8, 6655-6663, doi:10.5194/acp-8-6655-2008, 2008.

Guenther, A., Hewitt, C. N., Erickson, D., Fall, R., Geron, C., Graedel, T., Harley, P., Klinger, L., Lerdau, M., Mckay, W. A., Pierce, T., Scholes, B., Steinbrecher, R., Tallamraju, R., Taylor, J., and Zimmerman, P. A.: Global-Model of Natural Volatile Organic-Compound Emissions, J. Geophys. Res. Atmos., 100, 8873-8892, 1995.

Guenther, A., Karl, T., Harley, P., Wiedinmyer, C., Palmer, P. I., and Geron, C.: Estimates of global terrestrial isoprene emissions using MEGAN (Model of Emissions of Gases and Aerosols from Nature), Atmos. Chem. Phys., 6, 3181-3210, doi:10.5194/acp-63181-2006, 2006.

Hong, S.-Y. and Pan. H.-L.: Nonlocal boundary layer vertical diffusion in a medium-range forecast model, Mon. Wea. Rev., 124, 2322-2339. 1996

Hong, S.-Y., Noh Y., and Dudhia, J.: A new vertical diffusion package with an explicit treatment of entrainment processes, Mon. 
Wea. Rev., 134, 2318-2341. 2006

IMP (Instituto Mexicano el Petróleo): Investigación sobre material particulada y deterioro atmosférico, Subdirección de Protección Ambiental, 1994-1998, 1998.

Jayne J. T., Leard D. C., Zhang X., Davidovits P., Smith K. A., Kolb C. E., Worsnop D. R.: Development of an aerosol mass spectrometer for size and composition analysis of submicron particles, Aerosol Sci. Tech., 33, 49-70, 2000.

Jimenez, J. L., Jayne, J. T., Shi, Q., Kolb, C. E., Worsnop, D. R., Yourshaw, I., Seinfeld, J. H., Flagan, R. C., Zhang, X., Smith, K. A., Morris, J., and Davidovits, P.: Ambient Aerosol Sampling with an Aerosol Mass Spectrometer, J. Geophys. Res.-Atmos., 108, 8425, doi:10.1029/2001JD001213, 2003.

Kleinman, L. I., Springston, S. R., Wang, J., Daum, P. H., Lee, Y.-N., Nunnermacker, L. J., Senum, G. I., Weinstein-Lloyd, J., Alexander, M. L., Hubbe, J., Ortega, J., Zaveri, R. A., Canagaratna, M. R., and Jayne, J.: The time evolution of aerosol size distribution over the Mexico City plateau, Atmos. Chem. Phys., 9, 4261-4278, doi:10.5194/acp-9-4261-2009, 2009.

Lei, W., de Foy, B., Zavala, M., Volkamer, R., and Molina, L. T.: Characterizing ozone production in the Mexico City Metropolitan Area: a case study using a chemical transport model, Atmos. Chem. Phys., 7, 1347-1366, doi:10.5194/acp-7-1347-2007, 2007.

Lewandowski, P. A., Eichinger, W. E., Holder, H., Prueger, J., Wang, J., and Kleinman, L. I.: Vertical distribution of aerosols in the vicinity of Mexico City during MILAGRO-2006 Campaign, Atmos. Chem. Phys., 10, 1017-1030, doi:10.5194/acp-10-10172010, 2010.

Madronich, S.: Photodissociation in the atmosphere: 1. Actinic flux and the effect of ground reflections and clouds, J. Geophys. Res., 92, 9740-9752, 1987.

Molina, L. T. and Molina, M. J.: Air Quality in the Mexico Megacity: An Integrated Assessment, Kluwer Academic Publishers: Dordrecht, The Netherlands, 384 pp., 2002.

Molina, L. T., Kolb, C. E., de Foy, B., Lamb, B. K., Brune, W. H., Jimenez, J. L., Ramos-Villegas, R., Sarmiento, J., ParamoFigueroa, V. H., Cardenas, B., Gutierrez-Avedoy, V., and Molina, M. J.: Air quality in North America's most populous city overview of the MCMA-2003 campaign, Atmos. Chem. Phys., 7, 2447-2473, doi:10.5194/acp-7-2447-2007, 2007.

Molina, L. T., Madronich, S., Gaffney, J. S., Apel, E., de Foy, B., Fast, J., Ferrare, R., Herndon, S., Jimenez, J. L., Lamb, B., Osornio-Vargas, A. R., Russell, P., Schauer, J. J., Stevens, P. S., Volkamer, R., and Zavala, M.: An overview of the MILAGRO 2006 Campaign: Mexico City emissions and their transport and transformation, Atmos. Chem. Phys., 10, 8697-8760, doi:10.5194/acp-10-8697-2010, 2010.

Noh, Y., Cheon W.G., Hong S.-Y., and Raasch. S.: Improvement of the K-profile model for the planetary boundary layer based on large eddy simulation data, Bound.-Layer Meteorol., 107, 401427, 2003.

Pfister, G. G., Emmons, L. K., Hess, P. G., Lamarque, J.-F., Orlando, J. J., Walters, S., Guenther, A., Palmer, P. I., and Lawrence, P. J.: Contribution of isoprene to chemical budgets: A model tracer study with the NCAR CTM MOZART-4, J. Geophys. Res., 113, D05308, doi:10.1029/2007JD008948, 2008.

Raga, G. B., Castro, T., and Baumgardner, D.: The impact of megacity pollution on local climate and implications for the regional environment: Mexico City, Atmos. Environ., 35, 1805-1811, 2001.

Salcedo, D., Onasch, T. B., Dzepina, K., Canagaratna, M. R., Zhang, Q., Huffman, J. A., DeCarlo, P. F., Jayne, J. T., Mortimer, P., Worsnop, D. R., Kolb, C. E., Johnson, K. S., Zuberi, B., Marr, L. C., Volkamer, R., Molina, L. T., Molina, M. J., Cardenas, B., Bernabé, R. M., Márquez, C., Gaffney, J. S., Marley, N. A., Laskin, A., Shutthanandan, V., Xie, Y., Brune, W., Lesher, R., Shirley, T., and Jimenez, J. L.: Characterization of ambient aerosols in Mexico City during the MCMA-2003 campaign with Aerosol Mass Spectrometry: results from the CENICA Supersite, Atmos. Chem. Phys., 6, 925-946, doi:10.5194/acp-6-925-2006, 2006.

Schell, B., Ackermann, I. J., Hass, H., Binkowski, F. S., and Ebel, A.: Modeling the formation of secondary organic aerosol within a comprehensive air quality modeling system, J. Geophys. Res., 106, 28275-28293, 2001.

Seinfeld, J. and Pandis, S.: Atmospheric Chemistry and Physics: From Air Pollution to Climate Change, 2nd edn., John Wiley and Sons, Inc., 2006.

Shaw, W. J., Pekour, M. S., Coulter, R. L., Martin, T. J., and Walters, J. T.: The daytime mixing layer observed by radiosonde, profiler, and lidar during MILAGRO, Atmos. Chem. Phys. Discuss., 7, 15025-15065, doi:10.5194/acpd-7-15025-2007, 2007.

Skamarock, W. C., Klemp, J. B, Dudhia, J., Gill, D. O., Barker, D. M., Duda, M. G., Huang, X.-Y., Wang, W., and Powers, J. G.: A description of the advanced research WRF version 3, NCAR Technical Note, NCAR/TN-475+STR, 2008.

Stensrud, D. J.: Parameterization Schemes: Keys to Understanding Numerical Weather Prediction Models, Cambridge University Press, 2007.

Streit, G. E. and Guzman, F.: Mexico City Air Quality: Progress of an International Collaborative Project to Define Air Quality Management Options, Atmos. Environ., 30, 723-733, 1996.

Smith, J. N., Dunn, M. J., VanRecken, T. M., Iida, K., Stolzenburg, M. R., McMurry, P. H., and Huey, L. G.: Chemical composition of atmospheric nanoparticles formed from nucleation in Tecamac, Mexico: Evidence for an important role for organic species in nanoparticle growth, Geophys. Res. Lett., 35, L04808, doi:10.1029/2007GL032523, 2008.

Tie, X., S. Madronich, S. Walters, R. Zhang, P. Rasch, and W. Collins: Effect of clouds on photolysis and oxidants in the troposphere, J. Geophys. Res., 108, 4642, doi:10.1029/2003JD003659, 2003.

Tie, X., Madronich, S., Li, G., Ying, Z., Weinheimer, A., Apel, E., and Campos, T.: Simulation of Mexico City plumes during the MIRAGE-Mex field campaign using the WRF-Chem model, Atmos. Chem. Phys., 9, 4621-4638, doi:10.5194/acp-9-4621-2009, 2009.

Wallace, J. M. and Hobbs, P. V.: Atmospheric Science, An Introductory Survey, Second Survey, Elsevier, New York, NY, 483 pp.

Wang, J., Cubison, M. J., Aiken, A. C., Jimenez, J. L., and Collins, D. R.: The importance of aerosol mixing state and size-resolved composition on $\mathrm{CCN}$ concentration and the variation of the importance with atmospheric aging of aerosols, Atmos. Chem. Phys., 10, 7267-7283, doi:10.5194/acp-10-7267-2010, 2010.

Wexler, A. S., Lurman, F. W. and Seinfeld, J. H.: Modeling urban and regional aerosols, I. Model development, Atmospheric Environment, 28, 531-546, 1994. 
Whiteman, C. D., Zhong, S., Bian, X., Fast, J. D., and Doran, J. C.: Boundary layer evolution and regional-scale diurnal circulations over the Mexico Basin and Mexican Plateau, J. Geophys. Res., 105, 10081-10102, 2000.

Wiedinmyer, C., Quayle, B., Geron, C., Beloe, A., McKenzie, D., Zhang, X., O’Neill, S., and Klos Wynne, K.: Estimating emissions from fires in North America for air quality modeling, Atmos. Environ., 40, 3419-3432, 2006.
Yokelson, R., Urbanski, S., Atlas, E., Toohey, D., Alvarado, E., Crounse, J., Wennberg, P., Fisher, M., Wold, C., Campos, T., Adachi, K., Buseck, P. R., and Hao, W. M.: Emissions from forest fires near Mexico City, Atmos. Chem. Phys. Discuss., 7, 66876718, doi:10.5194/acpd-7-6687-2007, 2007.

Zaveri, R. A. and Peters, L. K.: A new lumped structure photochemical mechanism for large-scale applications, J. Geophys. Res., 104, 30387-30415, 1999. 